\title{
Optimum Particle Size for Gold-Catalyzed CO Oxidation
}

\author{
Jin-Xun Liu, ${ }^{\circledR}$ Ivo A. W. Filot, Yaqiong Su, Bart Zijlstra, and Emiel J. M. Hensen*(i) \\ Inorganic Materials Chemistry, Department of Chemistry and Chemical Engineering, Eindhoven University of Technology, \\ Eindhoven 5600 MB, Netherlands
}

\section{Supporting Information}

ABSTRACT: The structure sensitivity of gold-catalyzed CO oxidation is presented by analyzing in detail the dependence of $\mathrm{CO}$ oxidation rate on particle size. Clusters with less than 14 gold atoms adopt a planar structure, whereas larger ones adopt a threedimensional structure. The $\mathrm{CO}$ and $\mathrm{O}_{2}$ adsorption properties depend strongly on particle structure and size. All of the reaction barriers relevant to $\mathrm{CO}$ oxidation display linear scaling relationships with $\mathrm{CO}$ and $\mathrm{O}_{2}$ binding strengths as main reactivity descriptors. Planar and three-dimensional gold clusters exhibit different linear scaling relationship due to different surface topologies and different coordination numbers of the surface atoms. On the basis of these linear scaling relationships, firstprinciples microkinetics simulations were conducted to determine $\mathrm{CO}$ oxidation rates and possible rate-determining step of $\mathrm{Au}$ particles. Planar $\mathrm{Au}_{9}$ and three-dimensional $\mathrm{Au}_{79}$ clusters present the highest $\mathrm{CO}$ oxidation rates for planar and three-dimensional clusters, respectively. The planar $\mathrm{Au}_{9}$ cluster is much more active than the optimum $\mathrm{Au}_{79}$ cluster. A common feature of optimum $\mathrm{CO}$ oxidation performance is the intermediate binding strengths of $\mathrm{CO}$ and $\mathrm{O}_{2}$, resulting in intermediate coverages of $\mathrm{CO}, \mathrm{O}_{2}$, and $\mathrm{O}$. Both these optimum particles present lower performance than maximum Sabatier performance, indicating that there is sufficient room for improvement of gold catalysts for $\mathrm{CO}$ oxidation.

\section{INTRODUCTION}

Catalytic performance of dispersed metals is governed by the size of the (nano)particles and the local surface topology, as these determine the electronic structure of the surface atoms to which reactants bind. ${ }^{1}$ Differences in the binding energies affect surface coverages and intrinsic barriers of the relevant elementary bond-breaking and bond-making steps. Understanding structure sensitivity in detail promises to accelerate design of better catalysts. ${ }^{2}$ Much progress in this field has been possible through careful in situ characterization and kinetic testing of structurally well-defined model systems - often in the form of surface science models, but recently also increasingly by using nanoparticles-in combination with first-principles density functional theory (DFT) calculations of reaction mechanism. ${ }^{3-14}$ In nanoparticle catalysis, the structure sensitivity manifests itself as a strong dependence of surface atom-based turnover frequency on particle size, predominantly because of the exposure of a significant fraction of corner, edge, and step-edge atoms at the surface of these particles. ${ }^{4,14-20}$ When particles become clusters, well-developed facets disappear and quantum effects and local surface atom topology will start influencing catalytic reactivity.

A case in point of structure sensitivity is CO oxidation catalyzed by gold. ${ }^{4,15-18}$ Gold catalysis has attracted widespread attention of the scientific community since the discovery that small supported $\mathrm{Au}$ nanoparticles exhibit unusual high activity in the $\mathrm{CO}$ oxidation reaction. ${ }^{21-26}$ For instance, it has been demonstrated that Au nanoparticles with a size of $2-3 \mathrm{~nm}$ are optimum for $\mathrm{CO}$ oxidation in $\mathrm{Au} / \mathrm{TiO}_{2}$ catalysts. ${ }^{16}$ The role of the support in gold-catalyzed $\mathrm{CO}$ oxidation chemistry in such systems has recently been emphasized in recent years. ${ }^{27-33}$ Moreover, $\mathrm{Li}$ et al. presented that single $\mathrm{Au}$ atom can be dynamically formed by $\mathrm{CO}$ adsorption on oxide-supported $\mathrm{Au}$ clusters influencing $\mathrm{CO}$ oxidation mechanism and activity. ${ }^{34,35}$ Nørskov and co-workers mentioned that $\mathrm{CO}$ oxidation activity depends predominantly on the size of gold particles, regardless of the support. ${ }^{36,37}$ However, it is still an open question why $\mathrm{CO}$ oxidation activity is very sensitive to the gold particle size. Accordingly, it is interesting to explore the influence of size of very small clusters/nanoparticles of gold on $\mathrm{CO}$ oxidation.

Because small gold clusters can be synthesized and confirmed nowadays, ${ }^{38,39}$ it is desirable to study the intrinsic activity of $\mathrm{CO}$ oxidation on gaseous gold clusters. Interest in gold cluster catalysis for $\mathrm{CO}$ oxidation is growing. ${ }^{26,30,40-48}$ For instance, Whetten et al. found that the gaseous $\mathrm{Au}_{6}$ anion is capable of oxidizing $\mathrm{CO}$ at a 2 orders of magnitude higher rate than supported gold catalysts. ${ }^{40}$ Temperature-dependent radio frequency-ion trap mass spectrometry and first-principles simulations were conducted to investigate the reaction mechanism of $\mathrm{CO}$ oxidation by free $\mathrm{Au}_{2}{ }^{-}$ions in the presence

Received: December 26, 2017

Revised: February 28, 2018

Published: March 28, 2018 
of $\mathrm{O}_{2}$, and a metastable $\mathrm{Au}_{2} \mathrm{CO}_{3}{ }^{-}$was identified as an intermediate at low temperature. ${ }^{41}$ It has also been demonstrated in experiments by the Wang group that the $\mathrm{Au}_{18}{ }^{-}$cage compound displays higher reactivity toward $\mathrm{O}_{2}$ among $\mathrm{Au}_{n}{ }^{-}$clusters $(n=16-18){ }^{43}$ Using computational chemistry, Nørskov's group found that $\mathrm{CO}$ and $\mathrm{O}_{2}$ bind stronger to the low-coordinated $\mathrm{Au}$ atoms that appear on smaller particles. ${ }^{36,37}$ Häkkinen and co-workers emphasized that strong binding of molecular oxygen to gold clusters smaller than $2 \mathrm{~nm}$ contributes to lowering the activation barrier of $\mathrm{CO}$ oxidation. ${ }^{49}$ The work of Zeng also demonstrated that $\mathrm{CO}$ oxidation activity can be related to the adsorption energies of $\mathrm{CO}$ and $\mathrm{O}_{2}{ }^{10,50}$ Lee's investigation indicates that a delicate balance between $\mathrm{CO}$ and $\mathrm{O}_{2}$ adsorption energies is required to maximize $\mathrm{CO}$ oxidation activity on $\mathrm{Au}$ nanoparticles. ${ }^{51} \mathrm{~A}$ recent work used the concept of the orbital-wise coordination number as a reactivity descriptor for $\mathrm{CO}$ and $\mathrm{O}$ adsorption energies on extended gold surfaces and nanoparticles of varying size and shape. $^{52}$ It has also been mentioned that the greater structural flexibility of very small clusters may contribute to high catalytic activity. ${ }^{53,54}$ To the best of our knowledge, the binding properties of $\mathrm{CO}$ and $\mathrm{O}_{2}$ as well as the relationships between their adsorption energies and reaction barriers relevant to $\mathrm{CO}$ oxidation have not been systematically investigated yet.

Herein, we report a combined first-principles density functional theory (DFT) and microkinetics study of CO oxidation on gold clusters/nanoparticles, revealing important insights into the structure dependence of the $\mathrm{CO}$ oxidation reaction. A search strategy based on a genetic algorithm (GA) is employed to determine the global minimum structures of small $\mathrm{Au}_{n}(n=3-16$ and 20) clusters. Larger particles of 38, 55, and 79 gold atoms as well as a Wulff particle are constructed by use of the Wulff theorem using computed surface energies. The well-accepted $\mathrm{CO}$ oxidation mechanism involving OCOO as a reaction intermediate is systematically studied on these models. We explore in detail the relationship between $\mathrm{CO}$ oxidation barriers and $\mathrm{CO}$ and $\mathrm{O}_{2}$ adsorption energies for gold particles. Planar and three-dimensional (3D) Au structures exhibit different scaling relationships due to their different topology and distinct coordination number of surface $\mathrm{Au}$ atoms. Firstprinciples microkinetics simulations have been performed to compute reaction rates and determine possible rate-determining step for $\mathrm{CO}$ oxidation over these particles for the first time. Two types of volcano curves are identified for planar and threedimensional gold structures. The odd-numbered planar clusters are significantly more active than the three-dimensional clusters. This work will provide valuable insight relevant to the design of more active gold catalysts for $\mathrm{CO}$ oxidation.

\section{METHODS}

DFT Calculations. All spin-polarized density functional theory (DFT) calculations were conducted by using projector augmented wave $(\mathrm{PAW})^{55}$ potentials and the Perdew-Burke-

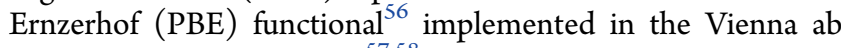
initio simulation package $\mathrm{s}^{57,58}$ code. The global minimum structures of $\mathrm{Au}$ clusters were obtained by using a genetic algorithm (GA) code with structures optimized by firstprinciples DFT calculations. The clusters were placed in a large cubic supercell (at least $15 \AA \times 15 \AA \times 15 \AA$ ) for the structure optimizations. Brillouin zone sampling was restricted to the $\Gamma$ point. All of the atoms in the clusters were allowed to relax. The energy cutoff of the plane wave basis set was $250 \mathrm{eV}$, and the convergence threshold for geometry optimizations was set to $1 \times 10^{-4} \mathrm{eV}$ for optimizing the structure of the clusters by the GA approach. Geometry optimization was deemed converged when the forces on each atom were below $0.05 \mathrm{eV}$ $\AA^{-1}$.

The morphologies of $\mathrm{Au}_{38}, \mathrm{Au}_{55}$, and $\mathrm{Au}_{79}$ clusters were obtained by the Wulff construction based on the surface energies of the extended surfaces. To obtain accurate surface energies, we have adopted $\mathrm{p}(1 \times 1)$ slab models with the atomic layers of at least $20 \AA$ separated by a vacuum of at least $15 \AA$. All of the atoms in the slab are fully relaxed with the force convergence criteria of $0.02 \mathrm{eV} \AA^{-1}$. The density of $k$-points was kept at $\sim 0.04 \AA^{-1}$ for the surface energies calculations. The surface energy $\left(E_{\text {surface }}\right)$ was determined as $E_{\text {surface }}=\left(E_{\text {slab }}-\right.$ $\left.N E_{\text {bulk }}\right) / 2 A$, where $E_{\text {slab }}$ and $E_{\text {bulk }}$ are the total energies of the slab and one bulk $\mathrm{Au}$ atom, respectively, $N$ is the number of $\mathrm{Au}$ atoms in the slab, and $A$ is the surface area.

$\mathrm{p}(3 \times 3)$ slab models were used for the calculation of $\mathrm{CO}$ oxidation mechanism on (111) and (100) surfaces, whereas $\mathrm{p}(2$ $\times 3)$ and $p(1 \times 3)$ slab models were used for $(211)$ and $(221)$ surfaces, respectively. All of the four surfaces were simulated by using four equivalent (111) atomic layers (except for (100) surface with five layers) slabs. Neighboring slabs were separated by a vacuum of $15 \AA$ to avoid self-interactions. All of the clusters were placed in a cubic supercell maintaining a vacuum gap of at least $10 \AA$ between the neighboring images. Calculations of the clusters were performed in the $\Gamma$-point, whereas a $3 \times 3 \times 1 k$-point mesh was used for all of the considered periodic surfaces, except for (211) surface with a 2 $\times 3 \times 1 k$-point mesh. The cutoff energy was set to $400 \mathrm{eV}$ for calculations of the $\mathrm{CO}$ oxidation reaction mechanism for all of the Au clusters and surfaces. For the clusters, all of the atoms were allowed to relax. The top two equivalent (111) layers and adsorbates were relaxed for the periodic models. The improved force-reversed method ${ }^{59}$ was used to determine the transition states (TSs) for CO oxidation, and a force tolerance of $0.02 \mathrm{eV}$ $\AA^{-1}$ was used. The nature of some of the TSs was verified by the climbing-image nudged elastic band methods. ${ }^{60,61}$ Vibrational mode analysis was done to verify the identified TSs.

Structure of Au Clusters. A standard genetic algorithm based on the principles of natural evolution was used. It includes four steps, involving generation of the initial population, optimization of the cluster structures, assigning the fitness, and generating new population by crossover, as introduced by Deaven and $\mathrm{Ho}^{62,63}$ as well as random mutations by moving of atoms. ${ }^{64}$ Each structure in the population is optimized at the DFT-PAW-PBE level. The calculated energies are used to determine the fitness, and the structures with lower energy have higher possibilities to be maintained in the population. ${ }^{65}$ Energies and bond distances are used to judge whether the two structures are the same to avoid multiple occurrences of one structure in the population. The cycle is terminated when no new structures are obtained for 80 cycles. Typically, several hundreds of structures have been optimized to obtain the global minimum structure of each $\mathrm{Au}$ cluster size.

Microkinetics Simulations. The calculated activation barriers were employed to compute the forward and backward rate constants for $\mathrm{CO}$ oxidation. For surface reactions, the rate constants for the forward and backward elementary reactions were determined by the Eyring equation ${ }^{66}$

$$
k=\frac{k_{\mathrm{b}} T}{h} \frac{Q^{\mathrm{TS}}}{Q} \mathrm{e}^{-E_{\mathrm{a}} / k_{\mathrm{b}} T}
$$



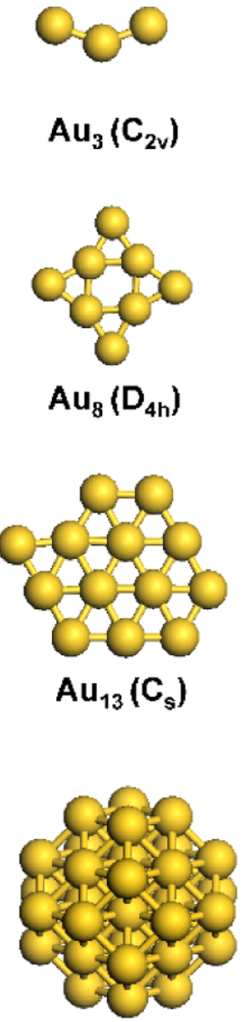

$\mathrm{Au}_{38}\left(\mathrm{O}_{\mathrm{h}}\right)$

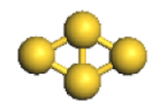

$\mathrm{Au}_{4}\left(\mathrm{D}_{2 \mathrm{~h}}\right)$

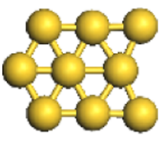

$\mathrm{Au}_{9}\left(\mathrm{C}_{2 \mathrm{v}}\right)$

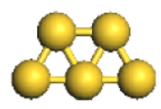

$\mathrm{Au}_{5}\left(\mathrm{C}_{2 \mathrm{v}}\right)$

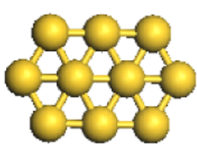

$\mathrm{Au}_{10}\left(\mathrm{D}_{2 \mathrm{~h}}\right)$

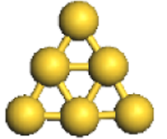

$\mathrm{Au}_{6}\left(\mathrm{D}_{3 \mathrm{~h}}\right)$

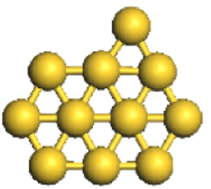

$\mathrm{Au}_{11}\left(\mathrm{C}_{\mathrm{s}}\right)$
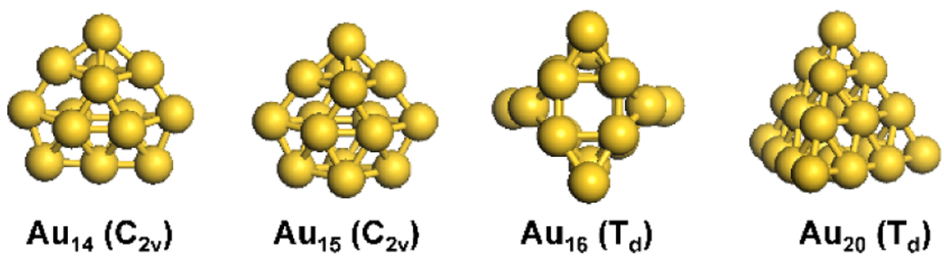

$\mathrm{Au}_{15}\left(\mathrm{C}_{2 \mathrm{v}}\right)$

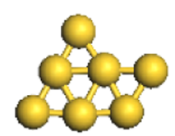

$\mathrm{Au}_{7}\left(\mathrm{C}_{\mathrm{s}}\right)$

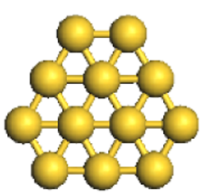

$\mathrm{Au}_{12}\left(\mathrm{D}_{3 \mathrm{~h}}\right)$

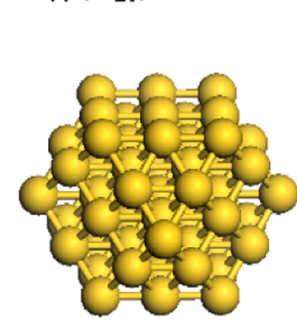

$\mathrm{Au}_{55}\left(\mathrm{O}_{\mathrm{h}}\right)$

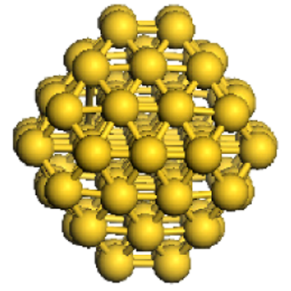

$\mathrm{Au}_{79}\left(\mathrm{O}_{\mathrm{h}}\right)$

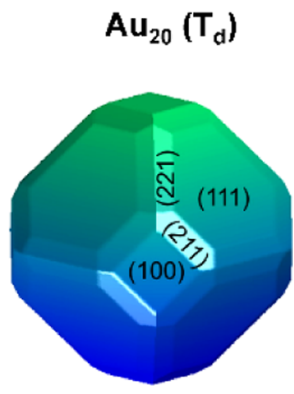

Wulff Shape

Figure 1. Most stable geometries and symmetries of $\mathrm{Au}$ clusters searched and obtained by genetic algorithm $\left(\mathrm{Au}_{3}-\mathrm{Au}_{20}\right)$ and $\mathrm{Wulff}-\mathrm{constructed}$ particles $\left(\mathrm{Au}_{38}, \mathrm{Au}_{55}, \mathrm{Au}_{79}\right.$, and a real Wulff particle).

where $k$ is the reaction rate constant in $\mathrm{s}^{-1} ; k_{\mathrm{b}}, T, h$, and $E_{\mathrm{a}}$ are the Boltzmann constant, temperature, Planck's constant, and the activation barrier, respectively; and $Q^{\mathrm{TS}}$ and $Q$ refer to the partition functions of the transition and ground states, respectively. As an approximation, the prefactor $A=\frac{k_{\mathrm{b}} T}{h} \frac{Q^{\mathrm{TS}}}{\mathrm{Q}}$ is set to $10^{13} \mathrm{~s}^{-1}$ for all of the elementary surface reactions.

For nonactivated molecular adsorption, the rate of adsorption is determined by the rate of surface impingement of gas-phase molecules. The flux of incident molecules is given by the Hertz-Knudsen equation ${ }^{67}$

$$
F=\frac{P}{\sqrt{2 \pi m k_{\mathrm{b}} T}}
$$

Therefore, the molecular adsorption rate constant can be written as

$$
k_{\mathrm{ads}}=\frac{P A^{\prime}}{\sqrt{2 \pi m k_{\mathrm{b}} T}} S
$$

with $P$ the partial pressure of the adsorbate in the gas phase, $A^{\prime}$ the surface area of the adsorption site, $m$ the mass of the adsorbate, and $S$ the sticking coefficient. The sticking coefficient used here is 1 for $\mathrm{CO}$ and $\mathrm{O}_{2}$ adsorptions.

For the desorption process, it is assumed that there are three rotational degrees of freedom and two translational degrees of freedom in the transition state. Accordingly, the rate of desorption is given by

$$
k_{\text {des }}=\frac{k_{\mathrm{b}} T^{3}}{h^{3}} \frac{A^{\prime}\left(2 \pi k_{\mathrm{b}}\right)}{\sigma \theta_{\text {rot }}} \mathrm{e}^{-E_{\text {des }} / k_{\mathrm{b}} T}
$$

where $\sigma$ and $\theta$ are the symmetry number and the characteristic temperature for rotation, respectively. $E_{\mathrm{des}}$ is the desorption energy.

The approach to microkinetics simulations has been presented in detail elsewhere. ${ }^{13,68}$ Differential equations for all of the surface reaction intermediates were constructed using the rate constants and the set of elementary reaction steps. For each of the $M$ components in the kinetic network, a single differential equation in the form

$$
r_{i}=\sum_{j=1}^{N}\left(k_{j} \nu_{i}^{j} \prod_{k=1}^{M} c_{k} \nu_{k}^{j}\right)
$$

is obtained. In this equation, $k_{j}$ is the elementary reaction rate constant (see eq 1), $\nu_{i}^{j}$ is the stoichiometric coefficient of component $i$ in elementary reaction step $k$, and $c_{k}$ is the concentration of component $k$ on the catalytic surface.

The $\mathrm{CO}$ oxidation rate is calculated by the in-house developed MKMCXX program. ${ }^{13,68,69}$ Steady-state coverages were calculated by integrating the ordinary differential equations (ODEs) in time until the changes in the surface coverages were very small. Because chemical systems typically give rise to stiff sets of ODEs, we have used the backward differentiation formula method for the time integration. ${ }^{68}$ The rates of the individual elementary reaction steps can be obtained based on the calculated steady-state surface coverages. 
In our simulations, the gas phase contained a mixture of $\mathrm{CO}$ and $\mathrm{O}_{2}$ in 1:5 molar ratio at a total pressure of 40 Torr, which is the same as the experimental reaction conditions. ${ }^{16}$

The elementary reaction steps that contribute to the rate control over the overall reaction can be determined by the degree of rate control (DRC) concept introduced by Campbell et al. ${ }^{70-72}$ For elementary step $i$, the degree of rate control $X_{\mathrm{RC}, i}$ can be defined as

$$
X_{\mathrm{RC}, i}=\frac{k_{i}}{r}\left(\frac{\partial r}{\partial k_{i}}\right)_{k_{j \neq i}, K_{i}}=\left(\frac{\partial \ln r}{\partial \ln k_{i}}\right)_{k_{j \neq i}, K_{i}}
$$

where $k_{i}, K_{i}$, and $r$ are the rate constants, equilibrium constant for step $i$, and the reaction rate, respectively. Furthermore, the DRC coefficients have to obey the sum rule over all steps $i$ in the mechanism in such a way that ${ }^{71}$

$$
\sum_{i} X_{\mathrm{RC}, i}=1
$$

\section{RESULTS}

Structure of Au Clusters and Nanoparticles. We employed a DFT-based genetic algorithm (GA) to determine the most stable structures of $\mathrm{Au}_{n}(n=3-16$ and 20) clusters (Figure 1). A general observation is that even-numbered $\mathrm{Au}_{n}$ clusters exhibit higher symmetry than odd-numbered ones. Clusters with 13 atoms or less have a planar (two-dimensional) structure, whereas larger ones adopt a three-dimensional structure. The found $\mathrm{Au}_{20}$ cluster employs a $T_{\mathrm{d}}$ symmetry that is in line with previous works, ${ }^{38,39}$ indicating the stability of our GA approach. The identified structures agree with previous quantum-chemical calculations as well as experimental IR data used to resolve the structure of neutral gas-phase gold clusters. $^{38,73-77}$

It is still challenging to experimentally determine the exact structure of larger clusters and nanoparticles. ${ }^{78}$ As the firstprinciples GA approach is too expensive to predict the structure of nanoparticles, we used the Wulff theorem to obtain the structures of gold particles with 38,55 , and 79 atoms, using computed surface energies of extended surfaces. For this purpose, 10 common surface terminations were considered (Table S1). We also constructed a Wulff particle based on these calculated surface energies, which should reflect the structure of a sufficiently large nanoparticle as an approximation, in which edge and corner effects can be neglected. ${ }^{79}$ These obtained three structures might not be the global minimum ones, but they can be served as models to investigate gold particle size effect theoretically. $\mathrm{CO}$ oxidations on the same structure of $\mathrm{Au}_{38}$ and $\mathrm{Au}_{79}$ clusters are studied theoretically before. ${ }^{80,81}$ The surface of such nanoparticle is enclosed by (111), (100), (211), and (221) facets (Figure 1).

The edge atoms of planar clusters have a coordination number between 1 and 4 . The surface metal atoms in the threedimensional clusters have coordination numbers between 3 and 9. For large (Wulff) nanoparticles, the lowest coordination number is 7 for corner atoms on (211) and (221) facets. These differences in coordination numbers might already suggest that planar $\mathrm{Au}$ clusters are more reactive than the three-dimensional ones. It is seen that the cohesive energy of the chosen 79-atom cluster is still appreciably lower than that of bulk Au. Similar to Pt clusters, ${ }^{82}$ the calculated cohesive energy in planar and threedimensional Au clusters is proportional to the number of atoms to the power of $-1 / 3$ (Figure S1). By extrapolating the cohesive energy to clusters of infinite size, the calculated cohesive energy is $-3.44 \mathrm{eV}$, which is slightly lower than the experimental value of $-3.81 \mathrm{eV}$ per atom. ${ }^{83}$ As well established, DFT-generalized gradient approximation underestimates the cohesive energy of bulk gold. ${ }^{84} \mathrm{Next}$, we will investigate the adsorption of $\mathrm{CO}, \mathrm{O}_{2}$, and $\mathrm{O}$ on these clusters as a proxy for their electronic structure. $\mathrm{CO}$ oxidation on the isomers of $\mathrm{Au}$ clusters with higher energies and support effect is out the scope of this work.

Adsorption of $\mathrm{O}_{2}, \mathrm{CO}$, and $\mathrm{O}$ Adsorption. We computed the favorable adsorption geometries of $\mathrm{CO}, \mathrm{O}_{2}$, and $\mathrm{O}$ on $\mathrm{Au}$ clusters and the four surfaces exposed in the Wulff particle. Consistent with previous findings, ${ }^{85,86} \mathrm{CO}$ and $\mathrm{O}_{2}$ prefer to adsorb at the apex site on small Au clusters (Figure S2). The trends in the resulting adsorption energies as a function of cluster size and surface are shown in Figure 2. Numerical values

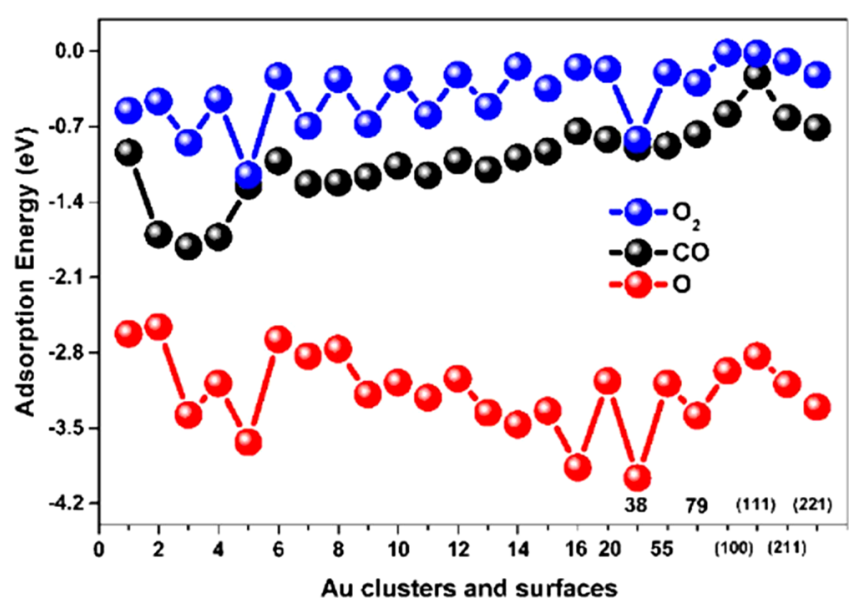

Figure 2. Calculated adsorption energies $(\mathrm{eV})$ of $\mathrm{O}_{2}$ (blue), $\mathrm{CO}$ (black), and atomic $\mathrm{O}$ (red) as a function of Au particle size. All of the adsorption energies are calculated with respect to the molecule or radical in the gas phase.

and configurations are collected in the Supporting Information (Figure S2 and Table S2). The adsorption energies of molecular oxygen on $\mathrm{Au}_{n}(n=1-16)$ clusters present a strong even-odd oscillation, with the stronger binding occurring for odd-numbered clusters. The reason is that odd-numbered $\mathrm{Au}$ clusters have one unpaired $6 \mathrm{~s}$ electron. To highlight these differences, a density of states (DOS) analysis was performed for $\mathrm{O}_{2}$ adsorption on $\mathrm{Au}_{7}$ and $\mathrm{Au}_{8}$ clusters (Figure 3a,b). In both cases, $\mathrm{O}_{2}$ binds to a corner $\mathrm{Au}$ atom with coordination number 2. Compared to $\mathrm{Au}_{8}$, the d-orbital of this $\mathrm{Au}$ atom is shifted to lower energies for $\mathrm{Au}_{7}$. Accordingly, the spin-down state of the $2 \pi^{*}$ orbital of adsorbed $\mathrm{O}_{2}$ is partially occupied for the $\mathrm{Au}_{7}$ cluster, which is not the case for the $\mathrm{Au}_{8}$ cluster. This difference results in more electron transfer from $\mathrm{Au}$ to the spindown component of the $2 \pi^{*}$ orbital of $\mathrm{O}_{2}$ on the $\mathrm{Au}_{7}$ cluster. This enhanced back-donation is the reason for the stronger binding of $\mathrm{O}_{2}$ to $\mathrm{Au}_{7}$ with respect to $\mathrm{Au}_{8}$. Moreover, due to the lower position of the d-bands of $\mathrm{Au}_{7}$, the hybridization with the $5 \sigma$ and $1 \pi$ orbitals of $\mathrm{O}_{2}$ is slightly stronger.

Aside from the even-odd oscillation, there is a trend of increasing adsorption energy of $\mathrm{O}_{2}$ with increasing cluster size. Adsorption on the three-dimensional clusters is slightly weaker than on clusters with a planar geometry. In general, $\mathrm{O}_{2}$ prefers to bind to a single $\mathrm{Au}$ atom, except for clusters containing 5, 13, 


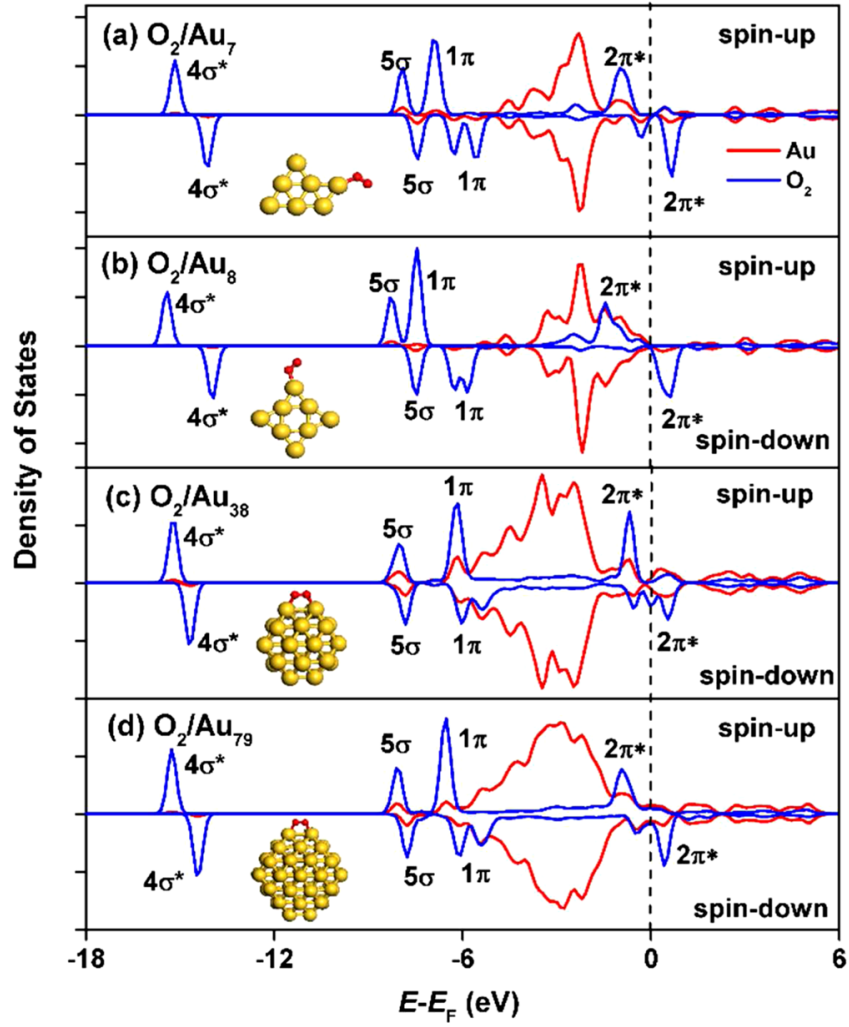

Figure 3. Spin-polarized density of state (DOS) and molecular orbitals of $\mathrm{O}_{2}$ adsorption on $\mathrm{Au}_{7}$ (a), $\mathrm{Au}_{8}$ (b), $\mathrm{Au}_{38}$ (c), and $\mathrm{Au}_{79}$ (d) clusters. The red and blue curves denote the DOS of $\mathrm{Au}$ atoms and $\mathrm{O}_{2}$, respectively. The $\mathrm{Au}$ atoms projected are those that bind with $\mathrm{O}_{2}$. The types of canonical labels of the CO orbitals are indicated.

38, and 79 atoms and on the (100), (211), and (221) surfaces, where $\mathrm{O}_{2}$ binds on two adjacent $\mathrm{Au}$ atoms. Binding to the extended surfaces is very weak, with a slight preference for the stepped (211) and (221) surfaces over the (100) and (111) terraces.

From Figure 2, it is apparent that $\mathrm{O}_{2}$ binds stronger on clusters containing 5 and 38 atoms than expected from the trend. We investigated this for the 38-atom cluster and found that $\mathrm{O}_{2}$ adsorption leads to a reconstruction of the surface atoms close to the adsorption site. The $\mathrm{Au}-\mathrm{Au}$ distance to which oxygen binds increases from 2.78 to $3.36 \AA$, which results in stronger interactions between oxygen's $5 \sigma$ and $1 \pi$ orbitals and the Au d-band (Figure 3c,d). Such an effect is also apparent for the $\mathrm{Au}_{5}$ cluster. Finally, it is worth noting that the strong size effect on the $\mathrm{O}_{2}$ adsorption energy observed for the oddnumbered clusters is nearly absent for the even-numbered clusters because the latter do not contain an unpaired electron. A second effect is that $\mathrm{O}_{2}$ adsorbs much weaker on the evennumbered clusters.

Compared to $\mathrm{O}_{2}$, the even-odd oscillations are hardly observed for $\mathrm{CO}$ adsorption on clusters containing between 1 and 16 atoms (Figure 2). Again taking $\mathrm{Au}_{7}$ and $\mathrm{Au}_{8}$ clusters as an example, we illustrate how $\mathrm{CO}$ and $\mathrm{O}_{2}$ adsorptions differ. Figure 4 clearly shows that the $2 \pi^{*}$ orbital of $\mathrm{CO}$ is too high in energy to hybridize with the d-band of Au. Accordingly, the unpaired electron in the odd-numbered clusters does not greatly affect $\mathrm{CO}$ adsorption. Relevant to $\mathrm{CO}$ oxidation is that $\mathrm{CO}$ adsorbs more strongly than $\mathrm{O}_{2}$ on all Au clusters. This is because of the stronger hybridization between $\mathrm{CO} 4 \sigma$ and $5 \sigma$ orbitals and the d-orbitals of the $\mathrm{Au}$ cluster, as can be

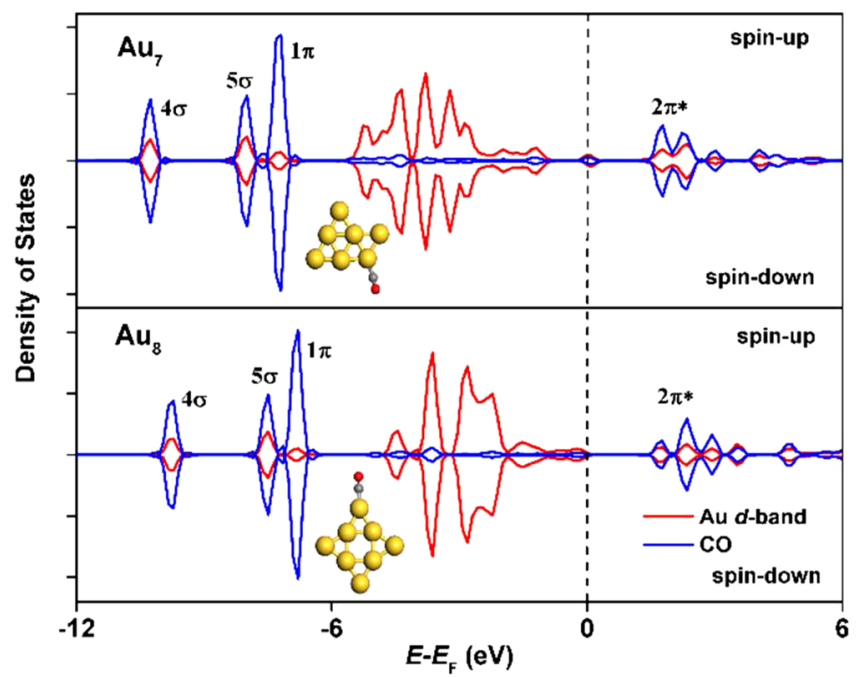

Figure 4. Spin-polarized density of state (DOS) and molecular orbitals of $\mathrm{CO}$ adsorbed on $\mathrm{Au}_{7}$ and $\mathrm{Au}_{8}$ clusters. The red and blue lines denote the DOS of $\mathrm{Au}$ atoms and $\mathrm{CO}$, respectively. The $\mathrm{Au}$ atoms projected are those that will bond with $\mathrm{CO}$. The canonical labels of the $\mathrm{CO}$ orbitals are indicated.

appreciated by comparing Figures 3 and 4. CO prefers to bind top or bridged to $\mathrm{Au}$ atoms with low coordination number on all of the $\mathrm{Au}_{n}$ clusters and surfaces (Figure S2). From Figure 2, it is observed that $\mathrm{CO}$ adsorbs strongly on $\mathrm{Au}_{n}(n=2-4)$ clusters with adsorption energies in the range of -1.70 to $-1.86 \mathrm{eV}$, in line with Nayak's findings. ${ }^{87}$ On larger clusters, $\mathrm{CO}$ adsorption strength decreases with increasing cluster size and $\mathrm{CO}$ adsorption energy varies from -1.25 to $-0.74 \mathrm{eV}$. CO adsorbs much weaker on the four considered $\mathrm{Au}$ surfaces $\left(E_{\mathrm{CO}}\right.$ $=-0.23$ to $-0.71 \mathrm{eV}$ ). As seen in Figure 2, $\mathrm{CO}$ always adsorbs stronger on the planar clusters compared to the threedimensional $\mathrm{Au}$ structures, which is due to the lower coordination numbers of the edge atoms in the planar $\mathrm{Au}$ clusters.

Binding energies of atomic $\mathrm{O}$ also present an even-odd oscillation for the gold clusters. Atomic $\mathrm{O}$ adsorbs stronger on the odd-numbered $\mathrm{Au}_{n}$ planar clusters. To understand this, we studied the DOS of $\mathrm{O}$ adsorbed on $\mathrm{Au}_{n}$ clusters with $n=4-7$ clusters (Figure S3). The antibonding states around the Fermi level are completely occupied only in the even-numbered clusters, explaining why the odd-numbered clusters bind atomic $\mathrm{O}$ stronger. The $\mathrm{O}$ atom adsorbs at the bridge site or in the threefold site of the clusters and surfaces except for the (100) surface, where fourfold coordination is adopted. The present DFT calculations show that $\mathrm{O}_{2}, \mathrm{CO}$, and atomic $\mathrm{O}$ adsorptions depend strongly on cluster size and surface topology.

CO Oxidation. Next, $\mathrm{CO}$ oxidation was investigated on selected $\mathrm{Au}_{n}$ clusters, i.e., planar clusters with $n=3-13$, threedimensional ones with $n=14,15,20,38$, and 79 , as well as the four extended surfaces exposed by the Wulff particle. As $\mathrm{O}_{2}$ does not dissociate on Au clusters and surfaces, ${ }^{28,37}$ an EleyRideal mechanism is not feasible. In the present work, we followed the well-accepted Langmuir-Hinshelwood mechanism ${ }^{88}$ involving reaction between adsorbed $\mathrm{CO}$ and $\mathrm{O}_{2}$. The mechanism consists of five elementary reactions

$$
\begin{aligned}
& \mathrm{CO}+* \leftrightarrows \mathrm{CO}^{*} \\
& \mathrm{O}_{2}+* \leftrightarrows \mathrm{O}_{2} *
\end{aligned}
$$




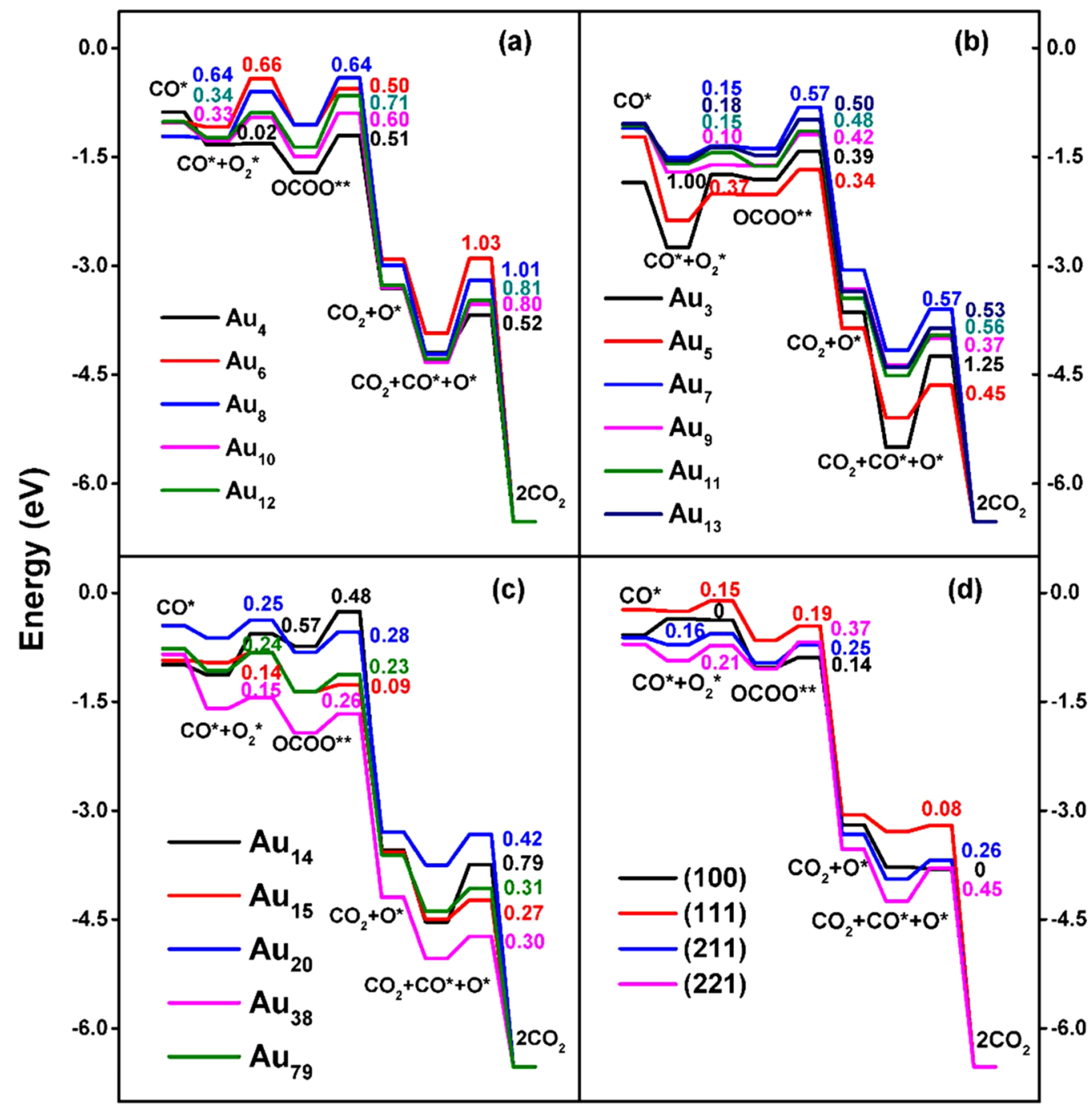

\section{Reaction coordinate}

Figure 5. Potential energy diagrams for $\mathrm{CO}$ oxidation on (a) planar even-numbered $\mathrm{Au}_{4}, \mathrm{Au}_{6}, \mathrm{Au}_{8}, \mathrm{Au}_{10}$, and $\mathrm{Au}_{12}$ clusters; (b) planar odd-numbered $\mathrm{Au}_{3}, \mathrm{Au}_{5}, \mathrm{Au}_{7}, \mathrm{Au}_{9}, \mathrm{Au}_{11}$, and $\mathrm{Au}_{13}$ clusters; (c) three-dimensional $\mathrm{Au}_{n}(n=14,15,20,38$, and 79) clusters; and (d) Au surfaces. The elementary reaction barrier heights $(\mathrm{eV})$ are indicated.

$$
\begin{aligned}
& \mathrm{CO}^{*}+\mathrm{O}_{2}^{*} \leftrightarrows \mathrm{OCOO}^{* *} \\
& \mathrm{OCOO}^{* *} \leftrightarrows \mathrm{CO}_{2}+\mathrm{O}^{*}+* \\
& \mathrm{CO}^{*}+\mathrm{O}^{*} \leftrightarrows \mathrm{CO}_{2}+2^{*}
\end{aligned}
$$

where * represents surface vacancy. The OCOO adduct formed by reaction of adsorbed $\mathrm{CO}$ and $\mathrm{O}_{2}$ binds with the $\mathrm{C}$ and one of the $\mathrm{O}$ atoms to the surface. The potential energy diagrams for the gold models explored in this section are shown in Figure 5 (numerical data in Table S3). As presented in Figures S4 and $\mathrm{S} 5$, optimized $\mathrm{CO}, \mathrm{O}_{2}$, and $\mathrm{O}$ adsorption configurations are considered as the initial states or final state to calculate the forward and backward reaction barriers. We neglected here possible lateral interactions. The presence of a support might change the structure of these Au clusters, which will influence the catalytic activity of $\mathrm{CO}$ oxidation. In addition, it is likely that active sites at the interface between $\mathrm{Au}$ clusters and the support will display different reactivities in $\mathrm{CO}$ oxidation. Although the importance of support effects in $\mathrm{CO}$ oxidation is clear, this is beyond the scope of the present work.
It is found that stronger adsorption of $\mathrm{CO}$ and $\mathrm{O}_{2}$ generally leads to a lower activation barrier for the formation of the OCOO intermediate, in line with previous findings. ${ }^{89-91}$ The formation of this intermediate involves a similar transition state on the considered clusters and surfaces (Figures S4 and S5). The reaction barrier for OCOO formation generally has an even-odd oscillation effect. The associated barriers vary from 0.10 to $0.37 \mathrm{eV}$ for odd-numbered $\mathrm{Au}_{5}-\mathrm{Au}_{13}$ clusters and from 0.33 to $0.66 \mathrm{eV}$ for even-numbered planar $\mathrm{Au}_{6}-\mathrm{Au}_{12}$ clusters. $\mathrm{CO}$ oxidation is much easier on the odd-numbered clusters compared to the neighboring even-numbered ones, which especially relates to the stronger binding of $\mathrm{O}_{2}$. However, $\mathrm{Au}_{4}$ shows deviant behavior in the sense that it is more reactive than $\mathrm{Au}_{3}$ and $\mathrm{Au}_{5}$ due to the highly exothermic formation of OCOO. The calculated reaction barriers are 1.00, 0.02, and $0.37 \mathrm{eV}$ for $\mathrm{Au}_{3}, \mathrm{Au}_{4}$, and $\mathrm{Au}_{5}$ clusters, respectively. For three-dimensional Au clusters and surfaces, OCOO intermediate formation is also facile with barriers between close to 0 and $0.25 \mathrm{eV}$. Only on the $\mathrm{Au}_{14}$ cluster, the barrier is substantially higher at $0.57 \mathrm{eV}$ due to its high endothermic reaction energy. 

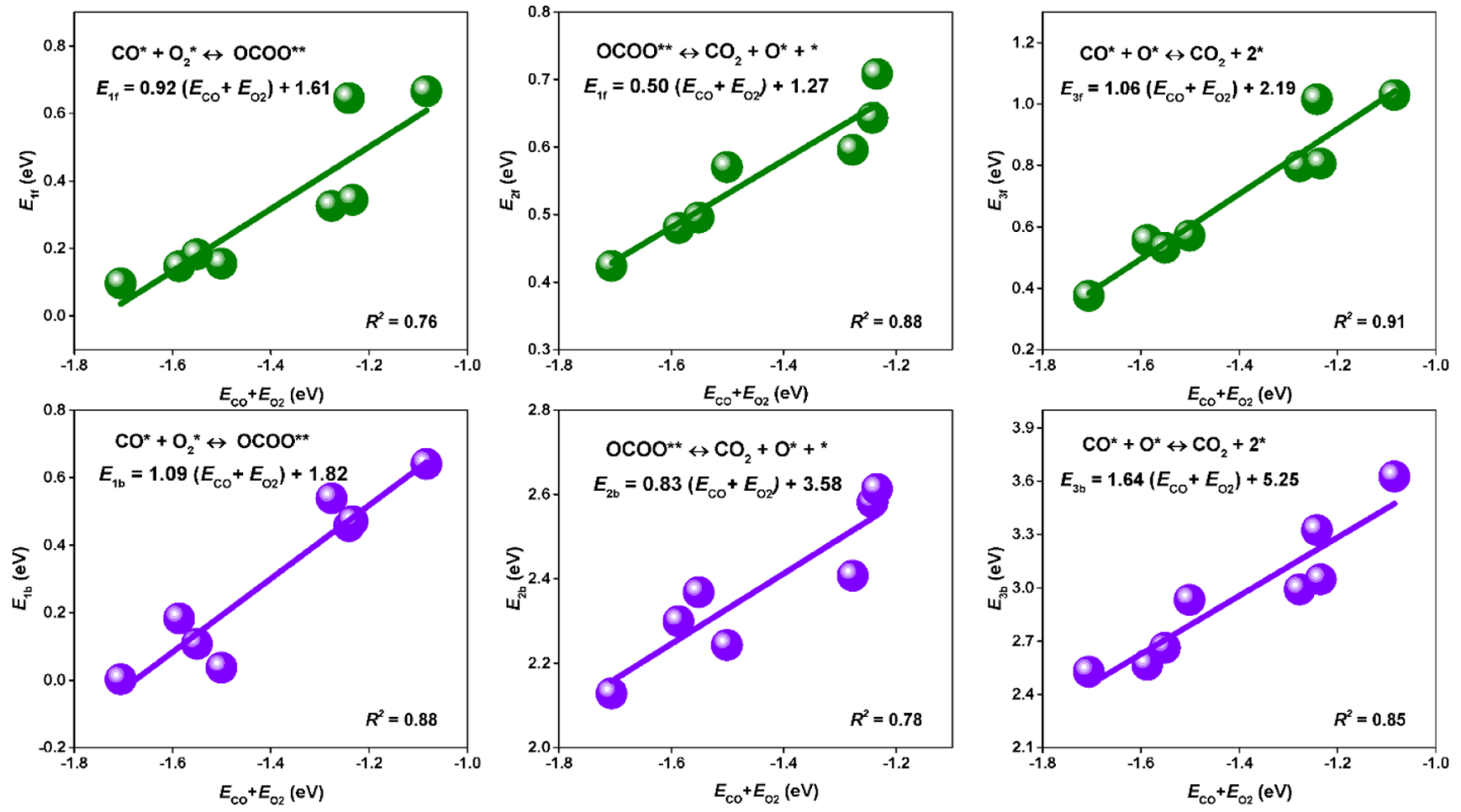

Figure 6. Linear scaling relations for $\mathrm{CO}$ oxidation on planar $\mathrm{Au}_{n}(n=6-13)$ clusters. The blue and purple points are the forward and backward reaction barriers for OCOO formation, OCOO decomposition, and atomic $\mathrm{O}$ removal reactions as a function of $E_{\mathrm{CO}}$ and $E_{\mathrm{O}_{2}}$ on $A u$ clusters, respectively. The fitted linear equations are indicated.
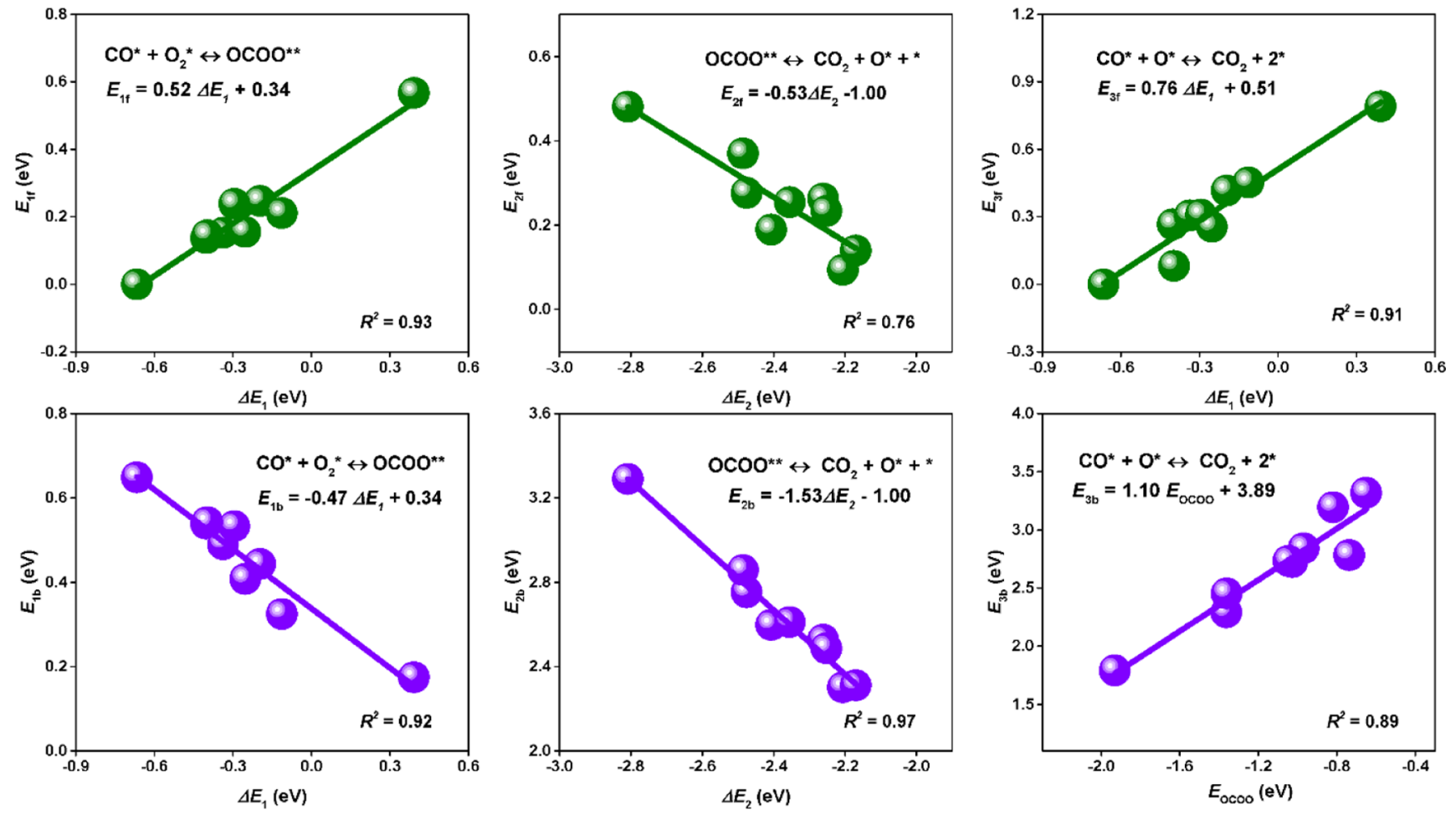

Figure 7. Linear scaling relations for $\mathrm{CO}$ oxidation on three-dimensional $\mathrm{Au}_{n}(n=14,15,20,38$, and 79) clusters and surfaces. The green and purple points are the forward and backward reaction barriers for OCOO formation, OCOO decomposition, and the removal of atomic $\mathrm{O}$ reactions as a function of $\Delta E_{1}\left(E_{\mathrm{OCOO}}-E_{\mathrm{CO}}-E_{\mathrm{O}_{2}}\right), \Delta E_{2}\left(E_{\mathrm{CO}_{2}}+E_{\mathrm{O}}-E_{\mathrm{OCOO}}\right)$, or $E_{\mathrm{OCOO}}$ on three-dimensional Au clusters and surfaces, respectively. The fitted linear equations are indicated.

OCOO decomposition is highly exothermic on all considered models. The barrier for OCOO decomposition is lower when the intermediate binds stronger. In the transition state, the $\mathrm{CO}_{2}$ fragment remains at the top site with the $\mathrm{O}$ atom 

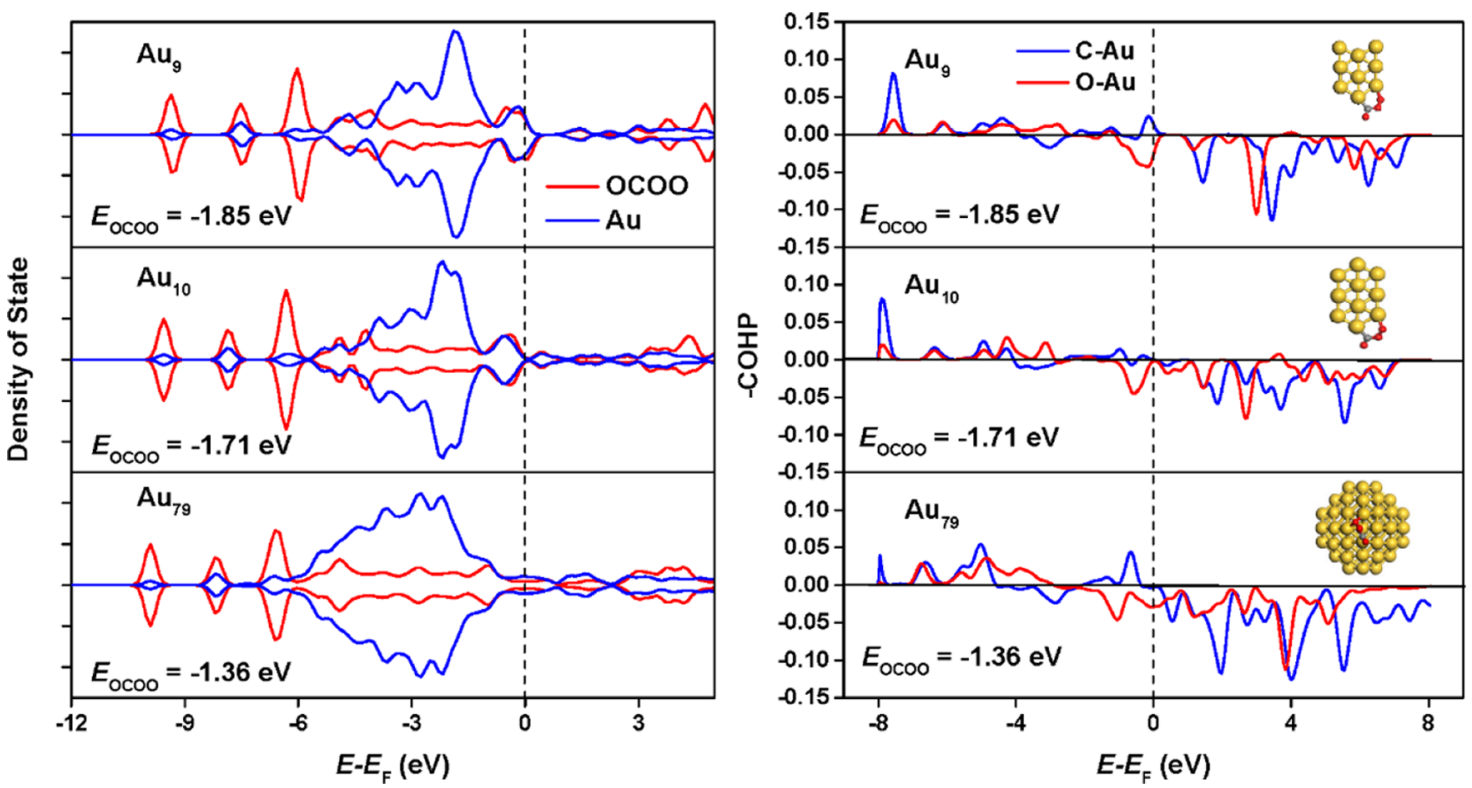

Figure 8. $\mathrm{DOS}$ and $\mathrm{COHP}$ analysis for OCOO adsorption on $\mathrm{Au}_{9}, \mathrm{Au}_{10}$, and $\mathrm{Au}_{79}$ clusters.

moving to an adjacent top site on planar clusters or bridge sites on three-dimensional Au clusters/particles (Figures S4 and S5). On planar clusters, OCOO dissociation barriers are in the 0.34-0.71 eV range with an odd-even variation. Compared to the even-numbered Au clusters, the neighboring odd-numbered ones exhibit a lower activation barrier for OCOO decomposition due to the activation of the $\mathrm{O}-\mathrm{O}$ bond in the OCOO intermediate, an effect also observed for $\mathrm{O}_{2}$ adsorption. The activation barrier is lower on the three-dimensional clusters and surfaces, ranging from 0.09 to $0.48 \mathrm{eV}$. It is associated with a higher (exothermic) reaction energy for these clusters. The $\mathrm{CO}$ oxidation cycle is closed by the $\mathrm{CO}^{*}+\mathrm{O}^{*} \rightarrow \mathrm{CO}_{2}+2^{*}$ reaction. For the planar clusters, the reaction barriers for this reaction range from 0.37 to $1.25 \mathrm{eV}$. Again, these barriers are higher than those encountered for the three-dimensional clusters and surface $\left(0-0.45 \mathrm{eV}\right.$, except for $\mathrm{Au}_{14}$, for which $E_{\text {act }}=0.79 \mathrm{eV}$ ).

The DFT calculations clearly show that $\mathrm{CO}$ oxidation is structure-sensitive on $\mathrm{Au}$ clusters and surfaces. For planar clusters, OCOO formation barriers are generally lower than barriers for OCOO decomposition and $\mathrm{O}$ removal except for $\mathrm{Au}_{3}$ and $\mathrm{Au}_{5}$ clusters, where OCOO decomposition is more feasible. For the three-dimensional clusters and surfaces, OCOO formation and decomposition barriers are comparable and lower than $O$ removal. Only for the (100) and (111) surfaces, the $\mathrm{O}$ removal step is facile. On the basis of these kinetic data, we expect that the cluster size will considerably affect $\mathrm{CO}$ oxidation kinetics.

Linear Scaling Relationships. Sabatier's principle is one of the most powerful concepts in heterogeneous catalysis, ${ }^{92}$ providing guidance in the selection of transition metals for specific catalytic reactions. ${ }^{93,94}$ It manifests itself in the form of volcano-shaped dependency of reaction rate or activation barriers on adsorption strength of reactants, reaction intermediates, and products. ${ }^{95,96}$ Its origins have been well studied for many reactions, and correlations have been formulated to describe reactivity, which strongly depends on activation barriers of elementary reaction steps, by more easily accessible parameters such as adsorption energies. The bestknown example of such (linear) scaling relationships is the one between the activation energy and the enthalpy change of an elementary reaction, known as the Brønsted-Evans-Polanyi (BEP) relation. ${ }^{97,98}$ The usefulness of this concept has been well established in computational studies, for instance, in predicting periodic activity trends. ${ }^{1,99-103}$

There are mainly eight kinetic parameters that determine the kinetics of the $\mathrm{CO}$ oxidation reaction: the adsorption energies of $\mathrm{O}_{2}$ and $\mathrm{CO}\left(E_{\mathrm{O}_{2}}\right.$ and $\left.E_{\mathrm{CO}}\right)$, forward and backward reaction barriers for OCOO formation $\left(E_{1 \mathrm{f}}\right.$ and $\left.E_{1 \mathrm{~b}}\right), \mathrm{CO}_{2}$ formation through OCOO decomposition $\left(E_{2 \mathrm{f}}\right.$ and $\left.E_{2 \mathrm{~b}}\right)$, and $\mathrm{O}$ removal $\left(E_{3 \mathrm{f}}\right.$ and $\left.E_{3 \mathrm{~b}}\right)$. We attempted to reduce the number of parameters by establishing linear scaling relations. In this way, we identified two types of linear scaling relationships, one for the planar clusters and one for the three-dimensional clusters and surfaces.

As shown in Figures 6 and 7, planar and three-dimensional clusters exhibit different linear scaling relationships. This is due to the different coordination numbers of the surface Au atoms on these two types of clusters, which results in different adsorption configurations of surface intermediates and, consequently, in different transition-state structures. For instance, the OCOO intermediate adsorbs on planar structures at the edge site with one $\mathrm{O}$ binding single $\mathrm{Au}$ atom, whereas the $\mathrm{O}$ atom in OCOO generally prefers to bind two surface $\mathrm{Au}$ atoms on three-dimensional Au clusters. Moreover, a DOS and crystal orbital Hamilton population (COHP) analysis of OCOO adsorption clearly shows that the less occupied antibonding orbital between $\mathrm{O}$ and $\mathrm{Au}$ atoms around the Fermi level leads to stronger adsorption on planar compared to three-dimensional gold clusters (Figure 8). As seen from Figures S4 and S5, the atomic $\mathrm{O}$ fragment moves to an adjacent top site on the planar clusters and to a bridge site on most three-dimensional clusters in the transition state for OCOO decomposition and $\mathrm{CO}+\mathrm{O} \rightarrow \mathrm{CO}_{2}$ steps.

Extremely small planar $\mathrm{Au}_{n}$ clusters $(n=3-5)$ are different from the other planar $\mathrm{Au}$ ones for $\mathrm{CO}$ oxidation because of their significantly different local surface atom arrangement (Figure 1). Accordingly, we omitted these three clusters in establishing the linear scaling relationships. We also excluded 

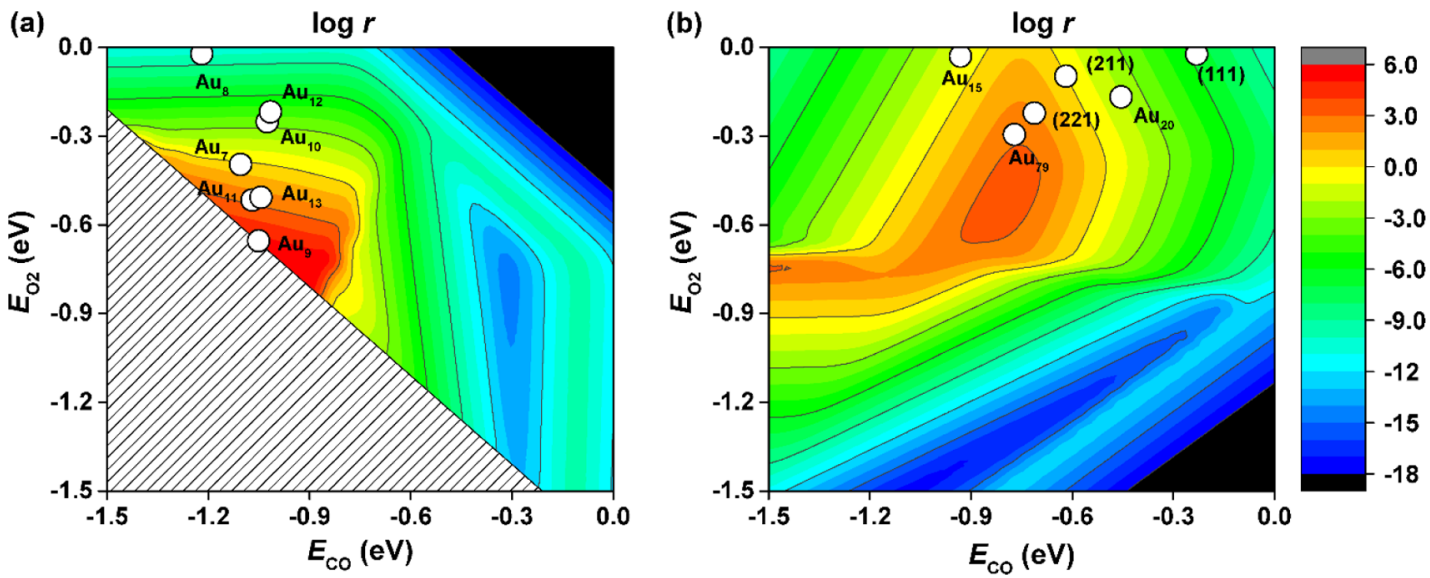

Figure 9. $\mathrm{CO}$ consumption rate $\left(\log r, r\right.$ in mol site $\mathrm{s}^{-1} \mathrm{~s}^{-1}$ unit) as a function of $\mathrm{CO}$ and $\mathrm{O}_{2}$ adsorption energies for (a) planar and (b) threedimensional Au structures. Microkinetics simulations were conducted at $T=350 \mathrm{~K}, p=40$ Torr, and a $\mathrm{O}_{2} / \mathrm{CO}$ ratio of $5 .{ }^{16}$ The dashed part in (a) indicates the area in phase space where the activation barriers of the OCOO formation step are negative and thus unphysical.

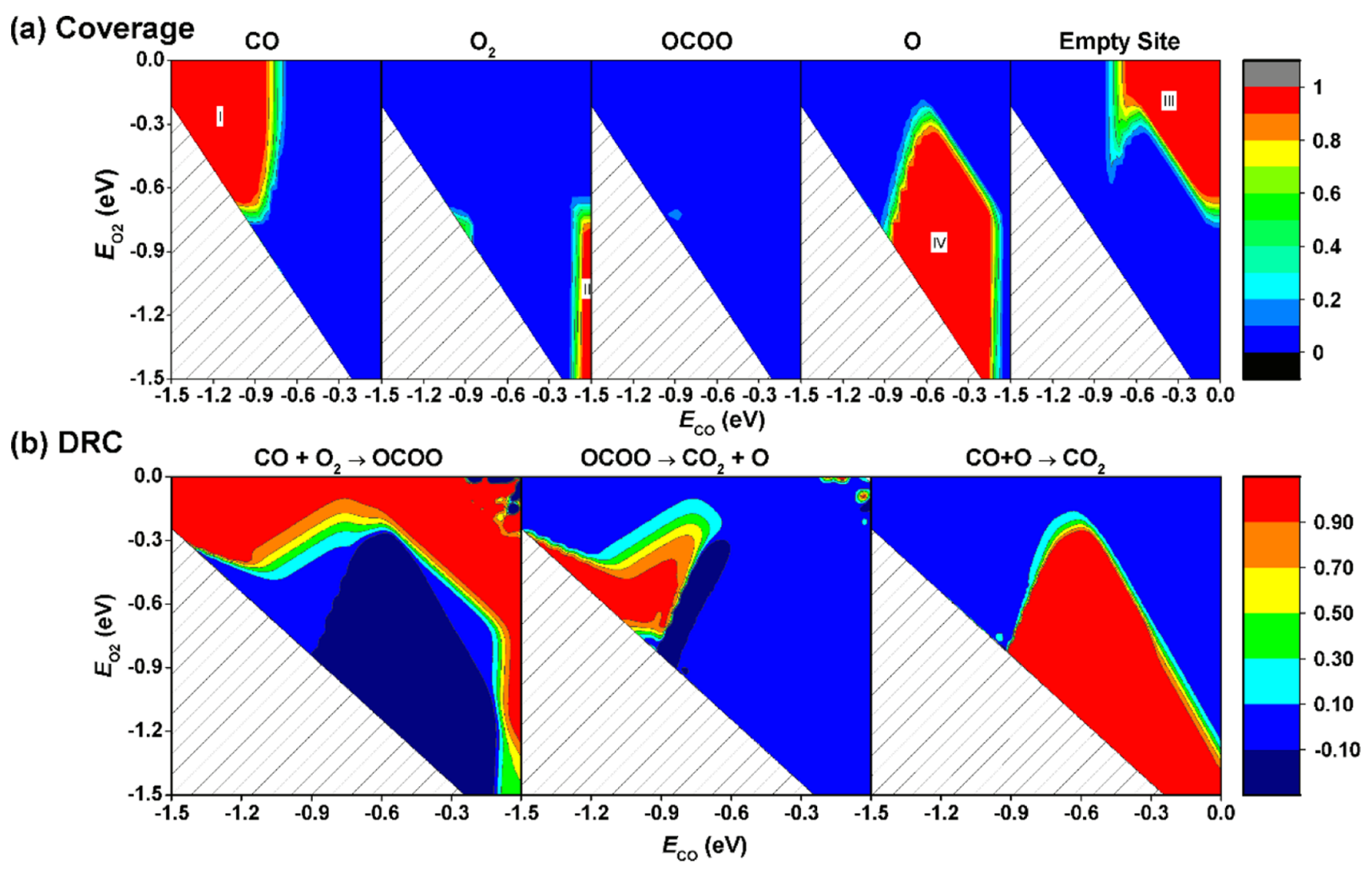

Figure 10. Steady-state coverage of the intermediates (a) and degree of rate control (b) as a function of $\mathrm{CO}$ and $\mathrm{O}_{2}$ adsorption energies on planar Au cluster. A positive DRC value for a particular elementary reaction step indicates that this step limits the reaction rate. The dashed parts indicate the area in phase space where the activation barriers of the OCOO formation step are negative and thus unphysical. Microkinetics simulations were conducted at $T=350 \mathrm{~K}, p=40$ Torr, and $\mathrm{O}_{2} / \mathrm{CO}=5: 1 .{ }^{16}$

the $\mathrm{Au}_{6}$ cluster in considering scaling relationships of $E_{2 \mathrm{f}}$ and $E_{2 \mathrm{~b}}$ versus $E_{\mathrm{CO}+\mathrm{O}_{2}}$ due to the large distortion of OCOO adsorption (Figure S4). The scaling relationship for $\mathrm{CO}$ oxidation on planar $\mathrm{Au}_{n}(n=6-13)$ clusters is presented in Figure 6. $\mathrm{CO}$ and $\mathrm{O}_{2}$ adsorption energies are correlated to relevant $\mathrm{CO}$ oxidation barriers on Au clusters. It is found that on planar Au clusters all of the forward and backward barriers for the three involved elementary reaction steps scale linearly with these adsorption energies. Therefore, $\mathrm{CO}$ and $\mathrm{O}_{2}$ adsorption energies can serve as descriptors for $\mathrm{CO}$ oxidation on planar Au clusters. Stronger adsorption of $\mathrm{CO}$ and $\mathrm{O}_{2}$ lead to a lower reaction barrier for $\mathrm{CO}$ oxidation. It is worth noting that $\mathrm{CO}$ adsorption on planar $\mathrm{Au}_{n}(n=6-13)$ is less structuresensitive with adsorption energies varying from -1.02 to -1.22 $\mathrm{eV}$. Therefore, reaction barriers relevant to $\mathrm{CO}$ oxidation can be approximated by the $\mathrm{O}_{2}$ adsorption energy on planar $\mathrm{Au}_{n}$ clusters.

For the three-dimensional Au clusters and surfaces, OCOO formation also follows the BEP relationship, i.e., the forward and backward reaction barriers $\left(E_{1 \mathrm{f}}\right.$ and $\left.E_{1 \mathrm{~b}}\right)$ are proportional to 


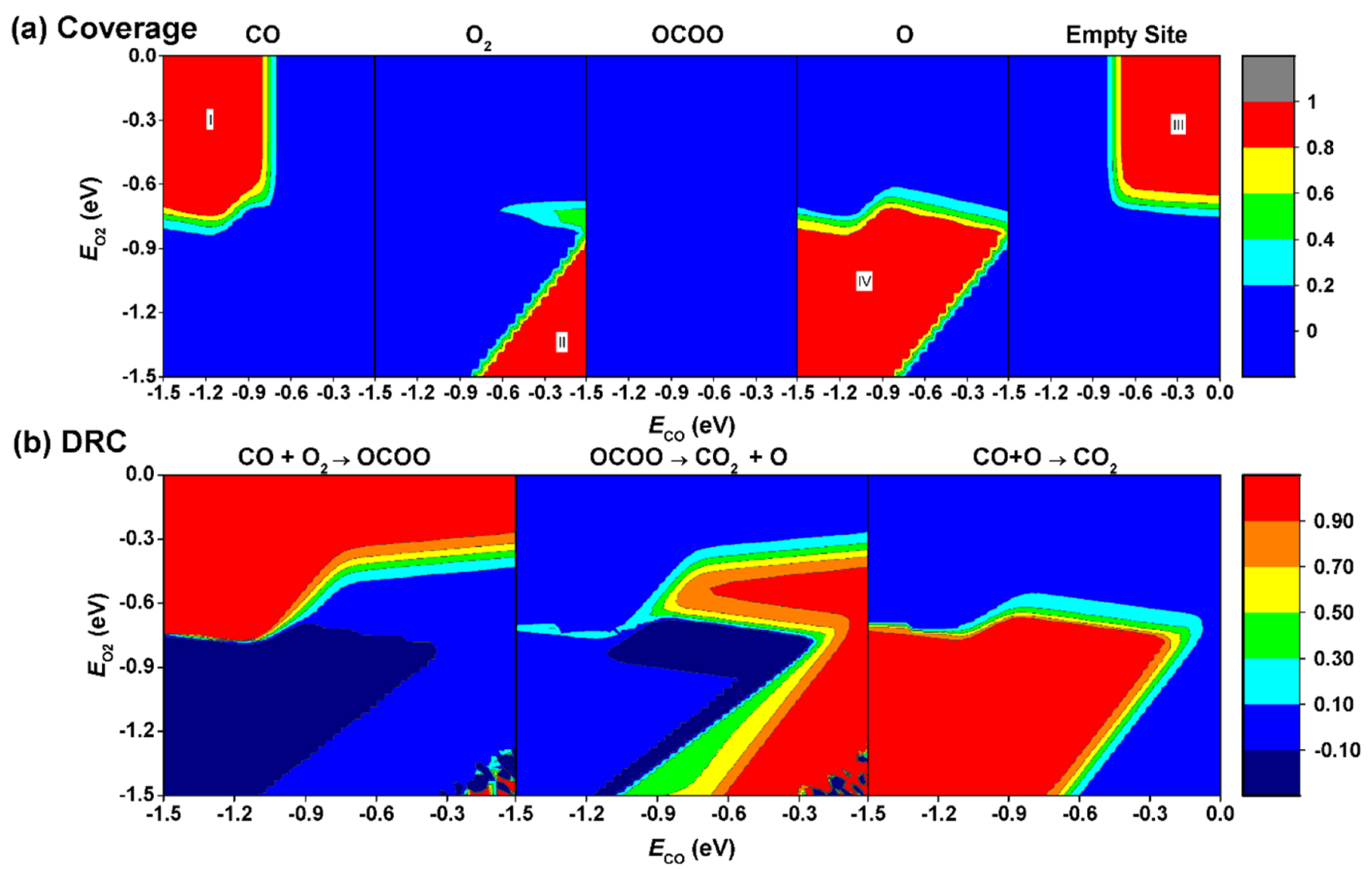

Figure 11. Steady-state coverage of the intermediates (a) and degree of rate control (b) as a function of $\mathrm{CO}$ and $\mathrm{O}_{2}$ adsorption energies on threedimensional $\mathrm{Au}$ clusters. A positive DRC value for a particular elementary reaction step indicates that this step limits the reaction rate. Microkinetics simulations were conducted at $T=350 \mathrm{~K}, p=40 \mathrm{Torr}$, and $\mathrm{O}_{2} / \mathrm{CO}=5: 1$, which is in line with experiment conditions for CO oxidation. ${ }^{16}$

the reaction enthalpy $\Delta E_{1}\left(\Delta E_{1}=E_{\mathrm{OCOO}}-E_{\mathrm{CO}}-E_{\mathrm{O}_{2}}\right)$. A lower reaction energy for OCOO formation results in a lower forward and higher backward reaction barrier for OCOO formation reaction (Figure 7). Similar to OCOO formation, the forward and backward reaction barriers $\left(E_{2 \mathrm{f}}\right.$ and $\left.E_{2 \mathrm{~b}}\right)$ for OCOO decomposition display linear scaling relationships with the reaction energy $\Delta E_{2}\left(\Delta E_{2}=E_{\mathrm{CO}_{2}}+E_{\mathrm{O}}-E_{\mathrm{OCOO}}\right)$. The negative slopes for the linear scaling relationship for the OCOO decomposition step are caused by the different $\mathrm{O}$ adsorptionand transition-state configurations among the various $3 \mathrm{D} \mathrm{Au}$ structures. It also indicates that forward and backward barriers for OCOO decomposition increase with the exothermicity of this reaction step. The transition state for OCOO decomposition has an early character. This trend shows that weaker adsorption of OCOO results in a higher barrier for its decomposition. The removal of atomic $\mathrm{O}$ by the elementary reaction step $\mathrm{CO}+\mathrm{O} \rightarrow \mathrm{CO}_{2}$ has a similar transition-state geometry to OCOO formation, involving the formation of a $\mathrm{C}-\mathrm{O}$ bond. The forward and backward reaction barriers for atomic $O$ removal scale linearly with $\Delta E_{1}$ and the adsorption energies of OCOO intermediate $\left(E_{\mathrm{OCOO}}\right)$, respectively. In fact, $\Delta E_{2}$ scales linearly with $\Delta E_{1}$ and the adsorption of OCOO intermediate $\left(E_{\mathrm{OCOO}}\right)$ is almost linearly related to $\mathrm{CO}$ adsorption $\left(E_{\mathrm{CO}}\right)$ on three-dimensional $\mathrm{Au}$ clusters and surfaces, as shown in Figure S6.

Therefore, all of the reaction barriers involved in $\mathrm{CO}$ oxidation can be expressed by $\mathrm{CO}$ and $\mathrm{O}_{2}$ adsorption energies as the reactivity descriptors for $\mathrm{CO}$ oxidation on threedimensional clusters and surfaces. It is clear that the scaling relationships between planar and three-dimensional Au clusters are different as a result of the different structures.

\section{DISCUSSION}

We use microkinetics simulations to compute catalytic $\mathrm{CO}$ oxidation rates for planar and three-dimensional Au structures using the in-house-developed MKMCXX code. ${ }^{13,68,69}$ For this purpose, we use both the kinetic parameters of particular clusters and scaling relations derived from them for planar and three-dimensional clusters. Figure 9 shows the dependencies of $\mathrm{CO}$ oxidation rate on $\mathrm{CO}$ and $\mathrm{O}_{2}$ adsorption energies for these cases.

The $\mathrm{Au}_{9}$ cluster has the highest predicted $\mathrm{CO}$ oxidation rate among the planar $\mathrm{Au}_{n}(n=7-13)$ clusters. The strong adsorption of $\mathrm{O}_{2}$ on $\mathrm{Au}_{9}$ results in low reaction barriers for the elementary reactions involved in $\mathrm{CO}$ oxidation. All of the oddnumbered $\mathrm{Au}$ clusters are more active than the even-numbered ones. For the planar clusters, stronger $\mathrm{O}_{2}$ adsorption enhances $\mathrm{CO}$ oxidation (Figure 9a). $\mathrm{CO}$ oxidation rates show a maximum for $\mathrm{CO}$ and $\mathrm{O}_{2}$ adsorption energies of about -0.9 and $-0.7 \mathrm{eV}$, respectively. The activities of the $\mathrm{Au}_{3}, \mathrm{Au}_{4}$, and $\mathrm{Au}_{5}$ clusters are $3 \times 10^{-15}, 3 \times 10^{3}$, and $3 \times 10^{-1} \mathrm{~mol} \mathrm{site}^{-1} \mathrm{~s}^{-1}$, respectively. The most active one, the $\mathrm{Au}_{4}$ cluster, is still significantly less active than the optimum $\mathrm{Au}_{9}$ cluster. Identification of the catalytic activity of gaseous $\mathrm{Au}$ clusters remains a substantial challenge in gold catalysis.

Figure 10a shows how surface coverage depends on the reactivity descriptors for planar Au clusters. A corresponding plot for the degree of control (DRC) $)^{70-72}$ is also shown in Figure $10 \mathrm{~b}$. There are four regimes for the planar clusters 
distinguished by the dominant surface species. In regime I, CO adsorbs so strongly on gold $\left(E_{\mathrm{CO}}<-0.9 \mathrm{eV}\right)$ that the surface becomes poisoned with this reactant. As a consequence of the low coverage of $\mathrm{O}_{2}$, formation of OCOO is the ratedetermining step (Figure 10b). However, when $\mathrm{O}_{2}$ adsorbs slightly stronger with the adsorption energy $\left(-0.7 \mathrm{eV}<E_{\mathrm{O}_{2}}<\right.$ $-0.3 \mathrm{eV})$, the $\mathrm{O}_{2}$ coverage will increase and OCOO dissociation will control the overall $\mathrm{CO}$ oxidation rate. In regime $\mathrm{II}$, the surface is poisoned by $\mathrm{O}_{2}$, as now $\mathrm{CO}$ adsorbs only weakly and $\mathrm{O}_{2}$ strongly $\left(E_{\mathrm{CO}}>-0.2 \mathrm{eV}\right.$ and $E_{\mathrm{O}_{2}}<-0.8$ $\mathrm{eV})$. OCOO formation remains the rate-controlling step due to the low coverage of $\mathrm{CO}$. In regime III, the surface coverages of $\mathrm{CO}$ and $\mathrm{O}_{2}$ are low on planar Au clusters when $\mathrm{CO}$ and $\mathrm{O}_{2}$ adsorb relatively weak $\left(E_{\mathrm{CO}}>-0.8 \mathrm{eV}\right.$ and $\left.E_{\mathrm{O}_{2}}>-0.9 \mathrm{eV}\right)$. OCOO formation still controls $\mathrm{CO}$ oxidation (Figure 10b). Regime IV is characterized by a high coverage of atomic $\mathrm{O}$ with intermediate $\mathrm{CO}$ and $\mathrm{O}_{2}$ adsorption energies $\left(E_{\mathrm{CO}}>-0.9 \mathrm{eV}\right.$ and $\left.E_{\mathrm{O}_{2}}<-0.3 \mathrm{eV}\right) . \mathrm{CO}_{2}$ formation through the $\mathrm{CO}+\mathrm{O} \rightarrow$ $\mathrm{CO}_{2}$ step is controlling the overall $\mathrm{CO}$ oxidation reaction rate, which is attributed to the low coverage of $\mathrm{CO}$. From the above discussion, we can deduce that reactant coverages and barriers, which mainly depend on $\mathrm{CO}$ and $\mathrm{O}_{2}$ bond strength, determine the catalytic $\mathrm{CO}$ oxidation.

The volcano-type dependency for CO oxidation on threedimensional $\mathrm{Au}$ clusters and extended surfaces is shown in Figure $9 \mathrm{~b}$. $\mathrm{Au}_{79}$ exhibits the highest $\mathrm{CO}$ oxidation reaction rate $\left(r=\sim 10^{3} \mathrm{~mol} \mathrm{site}^{-1} \mathrm{~s}^{-1}\right)$, followed by the Au (221) surface. The smaller $\mathrm{Au}_{14}, \mathrm{Au}_{15}$, and $\mathrm{Au}_{20}$ clusters have lower $\mathrm{CO}$ oxidation reaction rates $\left(<10^{0} \mathrm{~mol} \mathrm{site}^{-1} \mathrm{~s}^{-1}\right)$. The morphology of very large $\mathrm{Au}$ nanoparticles can be approximated by Wulff construction. Given the rates on the periodic surfaces, we predict that the catalytic $\mathrm{CO}$ oxidation activity of large $\mathrm{Au}$ particles is dominated by that of the (221) facet with a CO oxidation rate of $\sim 10^{2}$ mol site $\mathrm{s}^{-1} \mathrm{~s}^{-1}$. It should be stressed that the Wulff particle presents much lower activity than the $\mathrm{Au}_{79}$ nanoparticle. These findings suggest that medium-sized $\mathrm{Au}$ clusters $\left(1.3 \mathrm{~nm} / \mathrm{Au}_{79}\right)$ are optimal for $\mathrm{CO}$ oxidation for threedimensional $\mathrm{Au}$ particles. The maximum $\mathrm{CO}$ oxidation rate is obtained for $\mathrm{CO}$ and $\mathrm{O}_{2}$ adsorption energies of about -0.8 and $-0.4 \mathrm{eV}$ on the three-dimensional clusters and surfaces, respectively. Our work indicates that, for three-dimensional $\mathrm{Au}$ nanoparticles, there exists an intermediate optimum size of gold for CO oxidation, which is in line with the seminal work of the Goodman group. ${ }^{16}$

The intermediate coverages and DRCs are different between planar and three-dimensional Au clusters due to significant variations in the binding properties. Four distinct regimes can also be distinguished for the three-dimensional cluster (Figure 11a). Similar to planar Au clusters, $\mathrm{CO}$ will poison threedimensional $\mathrm{Au}$ clusters surface in regime $\mathrm{I}\left(E_{\mathrm{CO}}<-0.8 \mathrm{eV}\right.$ and $E_{\mathrm{O}_{2}}>-0.8 \mathrm{eV}$ ), where OCOO formation is controlling the CO oxidation rate. Unlike the planar Au clusters, the OCOO decomposition reaction becomes the rate-determining step in regime II $\left(E_{\mathrm{CO}}>-0.9 \mathrm{eV}\right.$ and $\left.E_{\mathrm{O}_{2}}<-0.9 \mathrm{eV}\right)$. Moreover, $\mathrm{CO}$ oxidation rate is limited by $\mathrm{OCOO}$ formation or dissociation in regime III $\left(E_{\mathrm{CO}}>-0.8 \mathrm{eV}\right.$ and $\left.E_{\mathrm{O}_{2}}<-0.8 \mathrm{eV}\right)$. The removal of atomic $\mathrm{O}\left(\mathrm{CO}+\mathrm{O} \rightarrow \mathrm{CO}_{2}\right)$ step is the rate-limiting step for $\mathrm{CO}$ oxidation when the three-dimensional Au cluster is fully covered by atomic $\mathrm{O}$ in regime IV.

Our work demonstrates the different catalytic behavior of small planar and larger three-dimensional gold clusters in $\mathrm{CO}$ oxidation. Due to the different coordination numbers of the surface atoms, binding properties of $\mathrm{CO}$ and $\mathrm{O}_{2}$ and reaction intermediates vary differently with cluster size for these two types of clusters. For each of the classes, linear scaling relations can be formulated that reliably predict the catalytic $\mathrm{CO}$ oxidation rate. Depending on the $\mathrm{CO}$ and $\mathrm{O}_{2}$ binding energies, different regimes can be distinguished on the basis of the most abundant reaction intermediate. The delicate balance between $\mathrm{CO}$ and $\mathrm{O}_{2}$ binding has a profound influence on $\mathrm{CO}$ oxidation activity. Optimum performance is obtained for intermediate bond strength of $\mathrm{CO}$ and $\mathrm{O}_{2}$ (i.e., respective optimum $\mathrm{CO}$ and $\mathrm{O}_{2}$ adsorption energies are ca. -0.9 and $-0.7 \mathrm{eV}$ for planar clusters and -0.8 and $-0.4 \mathrm{eV}$ for three-dimensional particles). Planar $\mathrm{Au}$ clusters generally require stronger $\mathrm{O}_{2}$ adsorption compared to the three-dimensional particles for optimum performance. The optimal planar Au cluster contains nine gold atoms and is predicted to have a higher $\mathrm{CO}$ oxidation rate than the optimum three-dimensional cluster comprising 79 atoms. The utility of the volcano approach is evident from our study: it demonstrates that there is room for improved $\mathrm{CO}$ oxidation performance of the most active planar and three-dimensional $\mathrm{Au}$ clusters by considering alloying or using a support to improve performance further.

\section{CONCLUSIONS}

DFT calculations have been performed to study $\mathrm{CO}$ oxidation on $\mathrm{Au}$ clusters and nanoparticles. Clusters with less than 14 gold atoms take on a planar shape, whereas larger ones adopt a three-dimensional shape. $\mathrm{CO}$ and $\mathrm{O}_{2}$ binding depends strongly on cluster size with strong even-odd oscillations noted for binding of oxygen atoms and molecules. All reaction barriers involved in $\mathrm{CO}$ oxidation display linear scaling relations with $\mathrm{CO}$ and $\mathrm{O}_{2}$ adsorption energies. These scaling relations are different for planar and three-dimensional Au clusters because of the different topologies of the surface and different coordination numbers of the surface atoms. On the basis of these scaling relationships and microkinetics simulations, it is found that planar $\mathrm{Au}_{9}$ and three-dimensional $\mathrm{Au}_{79}$ clusters are optimum for $\mathrm{CO}$ oxidation. Odd-numbered planar Au clusters have higher specific-mass activity than three-dimensional $\mathrm{Au}$ structures. Optimum $\mathrm{CO}$ oxidation rates occur for intermediate $\mathrm{CO}$ and $\mathrm{O}_{2}$ binding strengths and surface with moderate coverages $\mathrm{CO}, \mathrm{O}_{2}$, and $\mathrm{O}$. The planar structures are predicted to be substantially more active than the three-dimensional ones. The CO oxidation performance of the planar and threedimensional clusters is below the Sabatier optimum, suggesting there is room to improve catalytic performance, for instance, by introducing alloying elements or particular metal-support interactions.

\section{ASSOCIATED CONTENT}

\section{Supporting Information}

The Supporting Information is available free of charge on the ACS Publications website at DOI: 10.1021/acs.jpcc.7b12711.

Calculated cohesive energy versus the number of atoms (Figure S1); most favorable adsorption configurations of $\mathrm{CO}, \mathrm{O}_{2}$, and atomic $\mathrm{O}$ (Figure S2); projected density of states for $\mathrm{O}$ adsorption (Figure S3); Configurations for CO oxidation (Figures S4 and S5); linear relationship between the reaction energies (Figure $\mathrm{S} 6$ ); calculated surface energies (Table S1); calculated $\mathrm{CO}, \mathrm{O}_{2}$ and $\mathrm{O}$ 
adsorption energies (Tables S2 and S3); and Cartesian coordinates for optimized Au clusters (PDF)

\section{AUTHOR INFORMATION}

\section{Corresponding Author}

*E-mail: E.J.M.Hensen@tue.nl. ORCID

Jin-Xun Liu: 0000-0002-7499-4197

Emiel J. M. Hensen: 0000-0002-9754-2417

Notes

The authors declare no competing financial interest.

\section{ACKNOWLEDGMENTS}

The authors acknowledge financial support by NWO-VICI and NWO-TOP grants. The authors thank the Netherlands Organization for Scientific Research for access to the highperformance computing facilities.

\section{REFERENCES}

(1) Nørskov, J. K.; Bligaard, T.; Rossmeisl, J.; Christensen, C. H. Towards the Computational Design of Solid Catalysts. Nat. Chem. 2009, 1, 37-46.

(2) Van Santen, R. A. Complementary Structure Sensitive and Insensitive Catalytic Relationships. Acc. Chem. Res. 2009, 42, 57-66.

(3) Spencer, N. D.; Schoonmaker, R. C.; Somorjai, G. A. Structure Sensitivity in the Iron Single-Crystal Catalysed Synthesis of Ammonia. Nature 1981, 294, 643-644.

(4) Haruta, M. Gold as a Novel Catalyst in the 21st Century: Preparation, Working Mechanism and Applications. Gold Bull. 2004, $37,27-36$.

(5) Honkala, K.; Hellman, A.; Remediakis, I. N.; Logadottir, A.; Carlsson, A.; Dahl, S.; Christensen, C. H.; Nørskov, J. K. Ammonia Synthesis from First-Principles Calculations. Science 2005, 307, 555558.

(6) Roeffaers, M. B. J.; Sels, B. F.; Uji-i, H.; De Schryver, F. C.; Jacobs, P. A.; De Vos, D. E.; Hofkens, J. Spatially Resolved Observation of Crystal-Face-Dependent Catalysis by Single Turnover Counting. Nature 2006, 439, 572-575.

(7) Min, B. K.; Friend, C. M. Heterogeneous Gold-Based Catalysis for Green Chemistry: Low-Temperature CO Oxidation and Propene Oxidation. Chem. Rev. 2007, 107, 2709-2724.

(8) Jones, G.; et al. First Principles Calculations and Experimental Insight into Methane Steam Reforming over Transition Metal Catalysts. J. Catal. 2008, 259, 147-160.

(9) den Breejen, J. P.; Radstake, P. B.; Bezemer, G. L.; Bitter, J. H.; Frøseth, V.; Holmen, A.; de Jong, K. P. On the Origin of the Cobalt Particle Size Effects in Fischer-Tropsch Catalysis. J. Am. Chem. Soc. 2009, 131, 7197-7203.

(10) Gao, Y.; Shao, N.; Pei, Y.; Chen, Z.; Zeng, X. C. Catalytic Activities of Subnanometer Gold Clusters $\left(\mathrm{Au}_{16}-\mathrm{Au}_{18}, \mathrm{Au}_{20}\right.$, and $\mathrm{Au}_{27}-\mathrm{Au}_{35}$ ) for CO Oxidation. ACS Nano 2011, 5, 7818-7829.

(11) Zhou, K.; Li, Y. Catalysis Based on Nanocrystals with WellDefined Facets. Angew. Chem., Int. Ed. 2012, 51, 602-613.

(12) Liu, J.-X.; Su, H.-Y.; Sun, D.-P.; Zhang, B.-Y.; Li, W.-X. Crystallographic Dependence of CO Activation on Cobalt Catalysts: HCP Versus FCC. J. Am. Chem. Soc. 2013, 135, 16284-16287.

(13) Filot, I. A. W.; van Santen, R. A.; Hensen, E. J. M. The Optimally Performing Fischer-Tropsch Catalyst. Angew. Chem. 2014, 126, 12960-12964.

(14) Eren, B.; Zherebetskyy, D.; Patera, L. L.; Wu, C. H.; Bluhm, H.; Africh, C.; Wang, L.-W.; Somorjai, G. A.; Salmeron, M. Activation of $\mathrm{Cu}(111)$ Surface by Decomposition into Nanoclusters Driven by CO Adsorption. Science 2016, 351, 475-478.

(15) Valden, M.; Pak, S.; Lai, X.; Goodman, D. W. Structure Sensitivity of $\mathrm{CO}$ Oxidation over Model $\mathrm{Au} / \mathrm{TiO}_{2}$ Catalysts. Catal. Lett. 1998, 56, 7-10.
(16) Valden, M.; Lai, X.; Goodman, D. W. Onset of Catalytic Activity of Gold Clusters on Titania with the Appearance of Nonmetallic Properties. Science 1998, 281, 1647-1650.

(17) Lee, S.; Fan, C.; Wu, T.; Anderson, S. L. CO Oxidation on $\mathrm{Au}_{\mathrm{N}} /$ $\mathrm{TiO}_{2}$ Catalysts Produced by Size-Selected Cluster Deposition. J. Am. Chem. Soc. 2004, 126, 5682-5683.

(18) Chen, M.; Goodman, D. W. Catalytically Active Gold: From Nanoparticles to Ultrathin Films. Acc. Chem. Res. 2006, 39, 739-746.

(19) Bezemer, G. L.; Bitter, J. H.; Kuipers, H. P. C. E.; Oosterbeek, H.; Holewijn, J. E.; Xu, X.; Kapteijn, F.; van Dillen, A. J.; de Jong, K. P. Cobalt Particle Size Effects in the Fischer-Tropsch Reaction Studied with Carbon Nanofiber Supported Catalysts. J. Am. Chem. Soc. 2006, $128,3956-3964$.

(20) Zhang, X.; Liu, J.-X.; Zijlstra, B.; Filot, I. A. W.; Zhou, Z.; Sun, S.; Hensen, E. J. M. Optimum Cu Nanoparticle Catalysts for $\mathrm{CO}_{2}$ Hydrogenation Towards Methanol. Nano Energy 2018, 43, 200-209.

(21) Haruta, M.; Kobayashi, T.; Sano, H.; Yamada, N. Novel Gold Catalysts for the Oxidation of Carbon Monoxide at a Temperature Far Below $0{ }^{\circ} \mathrm{C}$. Chem. Lett. 1987, 16, 405-408.

(22) Iizuka, Y.; Fujiki, H.; Yamauchi, N.; Chijiiwa, T.; Arai, S.; Tsubota, S.; Haruta, M. Adsorption of CO on Gold Supported on $\mathrm{TiO}_{2}$. Catal. Today 1997, 36, 115-123.

(23) Grisel, R. J. H.; Nieuwenhuys, B. E. Selective Oxidation of CO, over Supported Au Catalysts. J. Catal. 2001, 199, 48-59.

(24) Guzman, J.; Carrettin, S.; Corma, A. Spectroscopic Evidence for the Supply of Reactive Oxygen During CO Oxidation Catalyzed by Gold Supported on Nanocrystalline $\mathrm{CeO}_{2}$. J. Am. Chem. Soc. 2005, $127,3286-3287$.

(25) Hashmi, A. S. K.; Hutchings, G. J. Gold Catalysis. Angew. Chem., Int. Ed. 2006, 45, 7896-7936.

(26) Herzing, A. A.; Kiely, C. J.; Carley, A. F.; Landon, P.; Hutchings, G. J. Identification of Active Gold Nanoclusters on Iron Oxide Supports for CO Oxidation. Science 2008, 321, 1331-1335.

(27) Molina, L. M.; Hammer, B. Active Role of Oxide Support During $\mathrm{CO}$ Oxidation at $\mathrm{Au} / \mathrm{MgO}$. Phys. Rev. Lett. 2003, 90, No. 206102.

(28) Liu, Z.-P.; Gong, X.-Q.; Kohanoff, J.; Sanchez, C.; Hu, P. Catalytic Role of Metal Oxides in Gold-Based Catalysts: A First Principles Study of CO Oxidation on $\mathrm{TiO}_{2}$ Supported Au. Phys. Rev. Lett. 2003, 91, No. 266102.

(29) Carrettin, S.; Concepción, P.; Corma, A.; Nieto, J. M. L.; Puntes, V. F. Nanocrystalline $\mathrm{CeO}_{2}$ Increases the Activity of $\mathrm{Au}$ for $\mathrm{CO}$ Oxidation by Two Orders of Magnitude. Angew. Chem., Int. Ed. 2004, $43,2538-2540$.

(30) Yoon, B.; Häkkinen, H.; Landman, U.; Wörz, A. S.; Antonietti, J.-M.; Abbet, S.; Judai, K.; Heiz, U. Charging Effects on Bonding and Catalyzed Oxidation of $\mathrm{CO}$ on $\mathrm{Au}_{8}$ Clusters on $\mathrm{MgO}$. Science 2005, 307, 403-407.

(31) Green, I. X.; Tang, W.; Neurock, M.; Yates, J. T. Spectroscopic Observation of Dual Catalytic Sites During Oxidation of $\mathrm{CO}$ on a Au/ $\mathrm{TiO}_{2}$ Catalyst. Science 2011, 333, 736-739.

(32) Song, W.; Hensen, E. J. M. A Computational DFT Study of CO Oxidation on a Au Nanorod Supported on $\mathrm{CeO}_{2}(110)$ : On the Role of the Support Termination. Catal. Sci. Technol. 2013, 3, 3020-3029.

(33) Liu, L. M.; McAllister, B.; Ye, H. Q.; Hu, P. Identifying an $\mathrm{O}_{2}$ Supply Pathway in CO Oxidation on $\mathrm{Au} / \mathrm{TiO}_{2}(110)$ : A Density Functional Theory Study on the Intrinsic Role of Water. J. Am. Chem. Soc. 2006, 128, 4017-4022.

(34) Wang, Y.-G.; Mei, D.; Glezakou, V.-A.; Li, J.; Rousseau, R. Dynamic Formation of Single-Atom Catalytic Active Sites on CeriaSupported Gold Nanoparticles. Nat. Commun. 2015, 6, No. 6511.

(35) Liu, J.-C.; Wang, Y.-G.; Li, J. Toward rational design of oxidesupported single-atom catalysts: atomic dispersion of gold on ceria. J. Am. Chem. Soc. 2017, 139, 6190.

(36) Lopez, N.; Janssens, T. V. W.; Clausen, B. S.; Xu, Y.; Mavrikakis, M.; Bligaard, T.; Nørskov, J. K. On the Origin of the Catalytic Activity of Gold Nanoparticles for Low-Temperature CO Oxidation. J. Catal. 2004, 223, 232-235. 
(37) Hvolbæk, B.; Janssens, T. V. W.; Clausen, B. S.; Falsig, H.; Christensen, C. H.; Nørskov, J. K. Catalytic Activity of Au Nanoparticles. Nano Today 2007, 2, 14-18.

(38) Gruene, P.; Rayner, D. M.; Redlich, B.; van der Meer, A. F. G.; Lyon, J. T.; Meijer, G.; Fielicke, A. Structures of Neutral $A_{7}, A u_{19}$, and $\mathrm{Au}_{20}$ Clusters in the Gas Phase. Science 2008, 321, 674-676.

(39) Li, J.; Li, X.; Zhai, H.-J.; Wang, L.-S. $A_{20}$ : A Tetrahedral Cluster. Science 2003, 299, 864-867.

(40) Wallace, W. T.; Whetten, R. L. Coadsorption of $\mathrm{CO}$ and $\mathrm{O}_{2}$ on Selected Gold Clusters: Evidence for Efficient Room-Temperature $\mathrm{CO}_{2}$ Generation. J. Am. Chem. Soc. 2002, 124, 7499-7505.

(41) Socaciu, L. D.; Hagen, J.; Bernhardt, T. M.; Wöste, L.; Heiz, U.; Häkkinen, H.; Landman, U. Catalytic $\mathrm{CO}$ Oxidation by Free $\mathrm{Au}_{2}{ }^{-}$: Experiment and Theory. J. Am. Chem. Soc. 2003, 125, 10437-10445.

(42) Corti, C. W.; Holliday, R. J.; Thompson, D. T. Progress Towards the Commercial Application of Gold Catalysts. Top. Catal. 2007, 44, 331-343.

(43) Huang, W.; Bulusu, S.; Pal, R.; Zeng, X. C.; Wang, L.-S. Structural Transition of Gold Nanoclusters: From the Golden Cage to the Golden Pyramid. ACS Nano 2009, 3, 1225-1230.

(44) Woodham, A. P.; Meijer, G.; Fielicke, A. Activation of Molecular Oxygen by Anionic Gold Clusters. Angew. Chem., Int. Ed. 2012, 51, 4444-4447.

(45) Liu, C.; Tan, Y.; Lin, S.; Li, H.; Wu, X.; Li, L.; Pei, Y.; Zeng, X. C. CO Self-Promoting Oxidation on Nanosized Gold Clusters: Triangular $\mathrm{Au}_{3}$ Active Site and $\mathrm{CO}$ Induced O-O Scission. J. Am. Chem. Soc. 2013, 135, 2583-2595.

(46) Wang, Y.-G.; Yoon, Y.; Glezakou, V.-A.; Li, J.; Rousseau, R. The Role of Reducible Oxide-Metal Cluster Charge Transfer in Catalytic Processes: New Insights on the Catalytic Mechanism of CO Oxidation on $\mathrm{Au} / \mathrm{TiO}_{2}$ from ab initio Molecular Dynamics. J. Am. Chem. Soc. 2013, 135, 10673-10683.

(47) Li, Z.-Y.; Yuan, Z.; Li, X.-N.; Zhao, Y.-X.; He, S.-G. CO Oxidation Catalyzed by Single Gold Atoms Supported on Aluminum Oxide Clusters. J. Am. Chem. Soc. 2014, 136, 14307-14313.

(48) Li, H.; Li, L.; Pedersen, A.; Gao, Y.; Khetrapal, N.; Jónsson, H.; Zeng, X. C. Magic-Number Gold Nanoclusters with Diameters from 1 to $3.5 \mathrm{~nm}$ : Relative Stability and Catalytic Activity for CO Oxidation. Nano Lett. 2015, 15, 682-688.

(49) Lopez-Acevedo, O.; Kacprzak, K. A.; Akola, J.; Häkkinen, H. Quantum Size Effects in Ambient CO Oxidation Catalysed by LigandProtected Gold Clusters. Nat. Chem. 2010, 2, 329-334.

(50) Li, L.; Gao, Y.; Li, H.; Zhao, Y.; Pei, Y.; Chen, Z.; Zeng, X. C. CO Oxidation on $\mathrm{TiO}_{2}$ (110) Supported Subnanometer Gold Clusters: Size and Shape Effects. J. Am. Chem. Soc. 2013, 135, 19336-19346.

(51) An, H.; Kwon, S.; Ha, H.; Kim, H. Y.; Lee, H. M. Reactive Structural Motifs of Au Nanoclusters for Oxygen Activation and Subsequent CO Oxidation. J. Phys. Chem. C 2016, 120, 9292-9298.

(52) Ma, X.; Xin, H. Orbitalwise Coordination Number for Predicting Adsorption Properties of Metal Nanocatalysts. Phys. Rev. Lett. 2017, 118, No. 036101.

(53) Häkkinen, H.; Abbet, S.; Sanchez, A.; Heiz, U.; Landman, U. Structural, Electronic, and Impurity-Doping Effects in Nanoscale Chemistry: Supported Gold Nanoclusters. Angew. Chem., Int. Ed. 2003, 42, 1297-1300.

(54) Barrio, L.; Liu, P.; Rodriguez, J. A.; Campos-Martin, J. M.; Fierro, J. L. G. Effects of Hydrogen on the Reactivity of $\mathrm{O}_{2}$ toward Gold Nanoparticles and Surfaces. J. Phys. Chem. C 2007, 111, 1900119008.

(55) Blöchl, P. E. Projector Augmented-Wave Method. Phys. Rev. B 1994, 50, No. 17953.

(56) Perdew, J. P.; Burke, K.; Ernzerhof, M. Generalized Gradient Approximation Made Simple. Phys. Rev. Lett. 1996, 77, No. 3865.

(57) Kresse, G.; Hafner, J. Ab Initio Molecular Dynamics for Liquid Metals. Phys. Rev. B 1993, 47, No. 558.

(58) Kresse, G.; Furthmüller, J. Efficient Iterative Schemes for Ab Initio Total-Energy Calculations Using a Plane-Wave Basis Set. Phys. Rev. B 1996, 54, No. 11169.
(59) Sun, K.; Zhao, Y.; Su, H.-Y.; Li, W.-X. Force Reversed Method for Locating Transition States. Theor. Chem. Acc. 2012, 131, No. 1118. (60) Henkelman, G.; Uberuaga, B. P.; Jónsson, H. A Climbing Image Nudged Elastic Band Method for Finding Saddle Points and Minimum Energy Paths. J. Chem. Phys. 2000, 113, No. 9901.

(61) Henkelman, G.; Jónsson, H. Improved Tangent Estimate in the Nudged Elastic Band Method for Finding Minimum Energy Paths and Saddle Points. J. Chem. Phys. 2000, 113, No. 9978.

(62) Deaven, D. M.; Ho, K. Molecular Geometry Optimization with a Genetic Algorithm. Phys. Rev. Lett. 1995, 75, No. 288.

(63) Daven, D. M.; Tit, N.; Morris, J. R.; Ho, K. M. Structural Optimization of Lennard-Jones Clusters by a Genetic Algorithm. Chem. Phys. Lett. 1996, 256, 195-200.

(64) Ding, X.-L.; Li, Z.-Y.; Meng, J.-H.; Zhao, Y.-X.; He, S.-G. Density-Functional Global Optimization of $\left(\mathrm{La}_{2} \mathrm{O}_{3}\right)_{\mathrm{N}}$ Clusters. J. Chem. Phys. 2012, 137, No. 214311.

(65) Cheng, L.; Cai, W.; Shao, X. A Connectivity Table for Cluster Similarity Checking in the Evolutionary Optimization Method. Chem. Phys. Lett. 2004, 389, 309-314.

(66) Eyring, H. The Activated Complex in Chemical Reactions. J. Chem. Phys. 1935, 3, No. 107.

(67) Nitoń, P.; Żywociński, A.; Fiałkowski, M.; Hołyst, R. A "NanoWindmill" Driven by a Flux of Water Vapour: A Comparison to the Rotating Atpase. Nanoscale 2013, 5, 9732-9738.

(68) Filot, I. A. W.; Broos, R. J.; van Rijn, J. P. M.; van Heugten, G. J. H. A.; van Santen, R. A.; Hensen, E. J. M. First-Principles-Based Microkinetics Simulations of Synthesis Gas Conversion on a Stepped Rhodium Surface. ACS Catal. 2015, 5, 5453-5467.

(69) Inorganic Materials Chemistry, 2017. http://www.mkmcxx.nl/ (accessed Dec 1, 2017).

(70) Campbell, C. T. Future Directions and Industrial Perspectives Micro- and Macro-Kinetics: Their Relationship in Heterogeneous Catalysis. Top. Catal. 1994, 1, 353-366.

(71) Campbell, C. T. Finding the Rate-Determining Step in a Mechanism: Comparing Dedonder Relations with the "Degree of Rate Control". J. Catal. 2001, 204, 520-524.

(72) Stegelmann, C.; Andreasen, A.; Campbell, C. T. Degree of Rate Control: How Much the Energies of Intermediates and Transition States Control Rates. J. Am. Chem. Soc. 2009, 131, 8077-8082.

(73) Remacle, F.; Kryachko, E. S. Structure and Energetics of Twoand Three-Dimensional Neutral, Cationic, and Anionic Gold Clusters $\mathrm{Au}_{5 \leq \mathrm{N} \leq 9} \mathrm{Z}(\mathrm{Z}=0, \pm 1)$. J. Chem. Phys. 2005, 122, No. 044304.

(74) Deka, A.; Deka, R. C. Structural and Electronic Properties of Stable $\mathrm{Au}_{\mathrm{n}}(\mathrm{n}=2-13)$ Clusters: A Density Functional Study. J. Mol. Struct.: THEOCHEM 2008, 870, 83-93.

(75) Lyalin, A.; Taketsugu, T. Adsorption of Ethylene on Neutral, Anionic, and Cationic Gold Clusters. J. Phys. Chem. C 2010, 114, 2484-2493.

(76) Nijamudheen, A.; Datta, A. Odd-Even Oscillations in Structural and Optical Properties of Gold Clusters. J. Mol. Struct.: THEOCHEM 2010, 945, 93-96.

(77) Gruene, P.; Butschke, B.; Lyon, J. T.; Rayner, D. M.; Fielicke, A. Far-IR Spectra of Small Neutral Gold Clusters in the Gas Phase. Z. Phys. Chem. 2014, 228, 337-350.

(78) Wang, J.; Wang, G.; Zhao, J. Density-Functional Study of $\mathrm{Au}_{\mathrm{N}}$ $(\mathrm{N}=2-20)$ Clusters: Lowest-Energy Structures and Electronic Properties. Phys. Rev. B 2002, 66, No. 035418.

(79) Filot, I. A. W.; Shetty, S. G.; Hensen, E. J. M.; van Santen, R. A. Size and Topological Effects of Rhodium Surfaces, Clusters and Nanoparticles on the Dissociation of CO. J. Phys. Chem. C 2011, 115, 14204-14212.

(80) Roldán, A.; González, S.; Ricart, J. M.; Illas, F. Critical Size for $\mathrm{O}_{2}$ Dissociation by Au Nanoparticles. ChemPhysChem 2009, 10, 348351.

(81) Tang, D.; Hu, C. DFT Insight into CO Oxidation Catalyzed by Gold Nanoclusters: Charge Effect and Multi-State Reactivity. J. Phys. Chem. Lett. 2011, 2, 2972-2977.

(82) Lin, X.; Ramer, N. J.; Rappe, A. M.; Hass, K. C.; Schneider, W. F.; Trout, B. L. Effect of Particle Size on the Adsorption of O and S 
Atoms on Pt: A Density-Functional Theory Study. J. Phys. Chem. B

2001, 105, 7739-7747.

(83) Kittel, C.; McEuen, P. Introduction to Solid State Physics; Wiley:

New York, 1996; Vol. 8.

(84) Xiao, L.; Tollberg, B.; Hu, X.; Wang, L. Structural Study of Gold Clusters. J. Chem. Phys. 2006, 124, No. 114309.

(85) Zhai, H.-J.; Kiran, B.; Dai, B.; Li, J.; Wang, L.-S. Unique CO Chemisorption Properties of Gold Hexamer: $\mathrm{Au}_{6}(\mathrm{CO})_{\mathrm{N}}{ }^{-}(\mathrm{N}=0-$ 3). J. Am. Chem. Soc. 2005, 127, 12098-12106.

(86) Zhai, H.-J.; Pan, L.-L.; Dai, B.; Kiran, B.; Li, J.; Wang, L.-S. Chemisorption-Induced Structural Changes and Transition from Chemisorption to Physisorption in $\mathrm{Au}_{6}(\mathrm{CO})_{\mathrm{N}}{ }^{-}(\mathrm{N}=4-9)$. J. Phys. Chem. C 2008, 112, 11920-11928.

(87) Wu, X.; Senapati, L.; Nayak, S. K.; Selloni, A.; Hajaligol, M. A Density Functional Study of Carbon Monoxide Adsorption on Small Cationic, Neutral, and Anionic Gold Clusters. J. Chem. Phys. 2002, 117, No. 4010.

(88) Liu, Z.-P.; Hu, P.; Alavi, A. Catalytic Role of Gold in Gold-Based Catalysts: A Density Functional Theory Study on the CO Oxidation on Gold. J. Am. Chem. Soc. 2002, 124, 14770-14779.

(89) Remediakis, I. N.; Lopez, N.; Nørskov, J. K. CO Oxidation on Gold Nanoparticles: Theoretical Studies. Appl. Catal., A 2005, 291, 13-20.

(90) Remediakis, I. N.; Lopez, N.; Nørskov, J. K. CO Oxidation on Rutile-Supported Au Nanoparticles. Angew. Chem. 2005, 117, 18581860.

(91) Liu, J.-X.; Liu, Z.; Filot, I. A. W.; Su, Y.; Tranca, I.; Hensen, E. J. M. CO Oxidation on Rh-Doped Hexadecagold Clusters. Catal. Sci. Technol. 2017, 7, 75-83.

(92) Ertl, G.; Knozinger, H.; Weitkamp, J. Handbook of Heterogeneous Catalysis; Wiley-VCH: New York, 1997.

(93) Jacobsen, C. J. H.; Dahl, S.; Clausen, B. S.; Bahn, S.; Logadottir, A.; Nørskov, J. K. Catalyst Design by Interpolation in the Periodic Table: Bimetallic Ammonia Synthesis Catalysts. J. Am. Chem. Soc. 2001, 123, 8404-8405.

(94) Toulhoat, H.; Raybaud, P. Kinetic Interpretation of Catalytic Activity Patterns Based on Theoretical Chemical Descriptors. J. Catal. 2003, 216, 63-72.

(95) Dumesic, J. A.; Rudd, D. F.; Aparicio, L. M.; Rekoske, J. E.; Treviño, A. A. The Microkinetics of Heterogeneous Catalysis; American Chemical Society: Washington, DC, 1993.

(96) Bligaard, T.; Nørskov, J. K.; Dahl, S.; Matthiesen, J.; Christensen, C. H.; Sehested, J. The Brønsted-Evans-Polanyi Relation and the Volcano Curve in Heterogeneous Catalysis. J. Catal. 2004, 224, 206-217.

(97) Evans, M. G.; Polanyi, M. Inertia and Driving Force of Chemical Reactions. Trans. Faraday Soc. 1938, 34, 11-24.

(98) Bronsted, J. N. Acid and Basic Catalysis. Chem. Rev. 1928, 5, 231-338.

(99) Cheng, J.; Hu, P.; Ellis, P.; French, S.; Kelly, G.; Lok, C. M. Bronsted-Evans-Polanyi Relation of Multistep Reactions and Volcano Curve in Heterogeneous Catalysis. J. Phys. Chem. C 2008, $112,1308-1311$.

(100) Liu, Z.-P.; Hu, P. General Trends in CO Dissociation on Transition Metal Surfaces. J. Chem. Phys. 2001, 114, No. 8244.

(101) Jiang, T.; Mowbray, D. J.; Dobrin, S.; Falsig, H.; Hvolbæk, B.; Bligaard, T.; Nørskov, J. K. Trends in CO Oxidation Rates for Metal Nanoparticles and Close-Packed, Stepped, and Kinked Surfaces. J. Phys. Chem. C 2009, 113, 10548-10553.

(102) Wang, S.; Temel, B.; Shen, J.; Jones, G.; Grabow, L. C.; Studt, F.; Bligaard, T.; Abild-Pedersen, F.; Christensen, C. H.; Nørskov, J. K. Universal Brønsted-Evans-Polanyi Relations for $\mathrm{C}-\mathrm{C}, \mathrm{C}-\mathrm{O}, \mathrm{C}-\mathrm{N}$, $\mathrm{N}-\mathrm{O}, \mathrm{N}-\mathrm{N}$, and O-O Dissociation Reactions. Catal. Lett. 2011, 141, 370-373.

(103) Michaelides, A.; Liu, Z.-P.; Zhang, C. J.; Alavi, A.; King, D. A.; $\mathrm{Hu}$, P. Identification of General Linear Relationships between Activation Energies and Enthalpy Changes for Dissociation Reactions at Surfaces. J. Am. Chem. Soc. 2003, 125, 3704-3705. 